\title{
EXPERIMENTAL ASSESSMENT OF THE OUT-OF-PLANE PERFORMANCE OF MASONRY BUILDINGS THROUGH SHAKING TABLE TESTS
}

Candeias, P.X, Campos Costa, A., Mendes, N., Costa, A.A., Lourenço, P.B.

\section{Abstract}

This paper presents the results of the LNEC-3D shaking table tests on two mock-ups, Brick House and Stone House, carried out in the scope of the workshop "Methods and challenges on the out-ofplane assessment of existing masonry buildings". The mock-ups have a U shape with one façade wall and two orthogonal sidewalls. The façade has a central opening and a gable on top, whereas the two sidewalls, acting as abutments, are either blind or have a window. A unidirectional seismic action, in the perpendicular direction to main wall, was applied. Out-of-plane behaviour of the façade was found, even if the response was clearly influenced by the presence of the window in one of the sidewalls, which led to significant torsion of the structure. The detailed description of the two tests and the conclusions are presented. The response of the mock-ups was evaluated based on the displacements, damage and collapse mechanisms developed as function of an increasing intensity earthquake testing protocol, in which a pre-processed strong ground motion component of the Christchurch (New Zealand) earthquake (February 21 ${ }^{\text {st }}, 2011$ ) was used.

Keywords: $\quad$ Clay brick masonry, Stone masonry, Shaking table tests, Seismic performance

\section{Introduction}

This paper focuses on the experimental study of the out-of-plane behaviour of masonry structures under seismic loading and provides a ground for the validation of the different approaches currently available for assessment of existing structures. For that purpose, tests were carried out in the LNEC-3D shake table with two mock-ups: one built using regular clay brick masonry with English bond and the other built using multi-leave granite stone masonry. The mock-ups have a $U$ shape with one façade wall and two orthogonal sidewalls. A unidirectional seismic action perpendicular to main wall was applied. Several experts were invited to predict the out-of-plane seismic capacity prior to the disclosure of the test results, in what is commonly known as a blind prediction test.

The main goal of the exercise was to promote a debate about the challenges of existing methods for the out-of-plane assessment of existing masonry buildings, leading to the definition of research needs, rather than evaluating the quantitative differences between the numerical predictions and the experimental results. Each participant was allowed to define the main control outputs according to the structural analysis method adopted, such as the collapse peak ground acceleration, ultimate displacement or energy dissipation.

A qualitative assessment was carried out with the purpose of identifying the trends in the predictions of the damage patterns and collapse mechanisms, which allow highlighting the pros and cons of the different methods, discussing their applicability for engineering assessment of existing buildings and 
comparing the different results with blind experimental tests. To this end, a reference response spectrum and some basic mechanical properties were supplied to the participants, while a clear indication of the performance levels reached and corresponding response spectrum scaling factors had to be indicated by the participants.

This paper presents the results of the LNEC-3D shaking table tests on the two mock-ups, Brick House and Stone House, including a detailed description of the tests and conclusions on the displacements, damage and collapse mechanisms. The results have been obtained for an increasing intensity earthquake testing protocol based on a pre-processed strong ground motion component of the Christchurch (New Zealand) February $21^{\text {st }}, 2011$, earthquake [1].

\section{Conceptual design of the blind prediction test}

As stated, the exercise was "blind" and it is possible to compare the "predictions" made with those measured during experimental testing. Each participant predicted the failure mode of the specimen and several response quantities, while the actual loading could only be determined during the course of testing.

There is hardly consensus regarding the out of plane behaviour of existing masonry buildings, with the understanding that the wall behaviour stems from the randomness, heterogeneity and anisotropy of the material. However, several other aspects can be raised, such as the loading direction with respect to the plane of the wall, in the first place. The walls are usually quite stiff and strong in their plane, whereas in the perpendicular direction they are quite flexible and weak. Thus, the in-plane response is typically controlled by shear mechanisms while the out-of-plane response is controlled by flexural mechanisms. In-plane shear mechanisms are often ductile, while out-of-plane flexure mechanism tend to be fragile. In addition, in case of irregular masonry, cyclic effects may lead to the premature collapse of the walls by disintegration. A second aspect is the connection between perpendicular walls. This aspect complements the previous one since seismic loading can occur in any direction. Therefore, the disposition of the walls in two orthogonal directions allows to have walls loaded in-plane and out-of-plane simultaneously. The contribution of the walls to the building performance depends on the effectiveness of the connection between them. Lastly, the presence of openings in the walls. These contribute not only to weaken the wall but may also shift the collapse mechanism from shear to flexure. The piers and spandrels formed by the openings are not only usually subject to flexure but also subject to larger stresses, when compared to the solid wall, posing greater demands.

Two types of masonry were considered for the mock-ups, namely brick and stone masonry, based on their representativeness in the existing stock of masonry buildings. For the former, slightly perforated clay bricks with an English bond arrangement were selected and, for the latter, irregular stones in multiple leaves were adopted. The mock-ups have three walls and a U-shaped plan: the façade, facing East, has a central opening and a gable on top, whereas the two sidewalls, acting as abutments, are either blind (South wall) or have a window (North wall). The façade also has an opening that in the case of the brick mock-up is a window and in the case of the stone mock-up is a 
door. The geometry of the mock-ups (designated as Brick House and Stone House) is shown in Figure 1 and Figure 2. A schematic detail of the wall corners is depicted in the centre of each figure.

The U-shaped houses were built on top of two $0.20 \mathrm{~m}$ thick reinforced concrete slabs, commonly used in the testing facility for the construction, transportation and fastening of mock-ups to the LNEC-3D shake table (Figure 3).The two mock-ups were tested up to collapse in the shake table under unidirectional seismic loading imposed in the direction perpendicular to the main façade. This way, the façade is loaded in the out-of-plane direction, while the sidewalls are loaded in-plane. Note that the lack of symmetry of the mock-up induces different responses in the two lateral walls, South and North, which provides significant torsion in the tests.

The choice of the accelerogram for the shake table tests took into consideration the aspects of duration, response spectrum and impulsive nature. Figure 4 presents the normalized response spectrum of the seismic action measured at the shaking table as well as the accelerogram envelope that was provided to the blind prediction challenge participants.

\section{Description of the test mock-ups and construction process}

The two test mock-ups have three masonry walls in a U-shaped plan. The façade, facing East, has a central opening and a gable on top whereas the two sidewalls, acting as abutments, are either blind (South wall) or have a window (North wall). Figure 5 depicts a general view of the two mock-ups just after the construction phase has ended.

\section{Brick House mock-up}

The construction of the Brick House mock-up started in mid-February 2014 and lasted for two weeks. The walls were built with fired clay bricks, with nominal dimensions of $235 \times 115 \times 70 \mathrm{~mm}^{3}$ and vertical holes, and an industrial pre-batched hydraulic lime mortar, with a compressive mean strength of $2 \mathrm{MPa}$. Figure 6 shows a sample of the clay bricks used in the construction of the Brick House. Cement was added to the mortar used in the first layer in order to increase the bond between the masonry wall and the reinforced concrete slab where the mock up was built.

The bricks were laid in an English bond arrangement, yielding a total thickness for the wall of around $23.5 \mathrm{~cm}$. The thickness of the joints was in the range from 1.5 to $1.8 \mathrm{~cm}$. Over the windows two timber lintels were placed side by side, with a $7 \mathrm{~cm}$ height, to match the height of the bricks. Figure 7 shows a view of the window on the North wall, with the timber lintels located at the level of a course of stretchers, and a detail of the parapet, where a course of headers is visible.

Six wallets of approximately $1.0 \times 1.0 \times 0.235 \mathrm{~m}^{3}$ were built for characterisation of the masonry mechanical strength. The wallets were built in the same way the as Brick House, using an English bond arrangement and the same type of bricks and mortar. Three wallets were tested in vertical compression and in diagonal compression aiming at obtaining the diagonal tensile (or shear) and compressive strength of masonry, respectively. The shear strength was determined according to the 
Frocht theory, in which the shear strength at the centre of the wallet is equal to $\sigma_{I}=0.5 \frac{P}{A}$, where $\mathrm{P}$ is the diagonal applied load and $A$ is the wallet transverse area. Table 1 presents the average values and coefficients of variation computed from the sample standard deviation: the average specific mass is $1890 \mathrm{~kg} / \mathrm{m}^{3}$, the average Young's modulus is $5170 \mathrm{MPa}$, the average compressive strength is $2.48 \mathrm{MPa}$ and the average tensile strength is equal to $0.10 \mathrm{MPa}$. The coefficients of variation range between $3 \%$ for the specific mass and $29 \%$ for the Young's modulus.

\section{Stone House mock-up}

The construction of the Stone House mock up started in the beginning of March 2014 and took around three weeks. The mock up was built using rough stones of various sizes, as in old masonry buildings. The walls have multiple leaves, the two outer ones with larger stones and the inner one with rubble masonry. The large stones were about 0.40 to $0.50 \mathrm{~m}$ in length, 0.20 to $0.30 \mathrm{~m}$ in height and $0.20 \mathrm{~m}$ in thickness. Smaller stones were used to fill the gap between the larger ones. The thickness of the outer leaves was approximately $0.20 \mathrm{~m}$ and the inner leave was approximately $0.10 \mathrm{~m}$, yielding a total wall thickness of about $0.50 \mathrm{~m}$. A lime based mortar, made of air lime and river sand in a 1:3 mix (per volume), was used in the construction of the walls. Similar to what was done in the Brick House, a small amount of cement was added to the mortar used in the first layer in order to increase the bond between the masonry wall and the reinforced concrete slab where the Stone House was built. Figure 8 shows the first course of stones in part of the East wall, from the corner up to the opening, and the North wall.

Over the two openings, a door on the East façade and a window on the North wall, two stone lintels were placed side by side. Figure 9 shows the aspect of the Stone House after construction and the individual stones were numbered before testing, in order to be able to track their individual motions from video image processing at a later stage.

In the meantime, six masonry wallets were built, aiming at obtaining the compressive and diagonal tensile (shear) strength of the stone masonry. These wallets had dimensions of $1.0 \mathrm{~m}$ by $1.0 \mathrm{~m}$ and thickness of $0.5 \mathrm{~m}$. Table 2 presents the average values and coefficients of variation computed from the sample standard deviation: the average specific mass is around $2360 \mathrm{~kg} / \mathrm{m}^{3}$, the average Young's modulus is $2080 \mathrm{MPa}$, the average compressive strength is $5.44 \mathrm{MPa}$ and the average shear strength is equal to $0.22 \mathrm{MPa}$. The coefficients of variation range between $1 \%$ for the specific mass and $43 \%$ for the Young's modulus.

\section{The LNEC Earthquake Engineering testing facility}

LNEC owns a large-scale experimental facility for seismic testing of structures which is part of the European Seismic Engineering Research Infrastructures and whose construction was partly financed by the European Union. The Earthquake Engineering and Structural Dynamics Division operates this facility for R\&D and industrial testing activities. 
The activity carried out in this LNEC testing facility aims at assessing the performance of structures subjected to dynamic and seismic loadings. The tests are carefully setup in order to simulate models with similar conditions to the real prototypes and measure the relevant effects, which are necessary for performance assessment. The preparation and operation of the shaking table follows standard protocols to achieve the targets proposed. Data analysis uses advanced techniques in the fields of signal processing, dynamics of structures and earthquake engineering to achieve the best results. These aspects ensure that the tests carried out meet high quality standards. General information on the laboratory can be found in [2].

\section{Instrumentation Setup}

The instrumentation of the two mock-ups was carried out using two types of sensors for measuring the response of the structure as well as the input signals on the shake table: i) 20 accelerometers; and ii) 6 linear variable displacement transducers (LVDTs). To measure the shake table motion one accelerometer was used, placed in the middle of the foundation slab in the transverse direction (Acc_ST), and the transverse actuator control LVDT (PosT).

The setup of the accelerometers is presented in Figure 10, only for the Brick House mock-up as the Stone House mock-up is similar. The measurements were made with unidirectional accelerometers placed in different locations. Fifteen accelerometers, identified with the symbol $\bullet$, were installed to measure the out-of-plane acceleration, three accelerometers, identified with the symbol $\mathbf{w}$, were used to measure the in-plane acceleration, in addition to one accelerometer in the vertical position (- $\mathbf{l}$ ) and one accelerometer in the rigid foundation slab. The accelerometers were directly connected to the mock-ups inside steel capsules in order to protect them from damage during the probable collapse.

The setup of the six LVDTs used to measure the relative displacement of the out-of-plane motion of the façade as illustrated in Figure 11. The LVDT placed near the base aimed at evaluating the sliding between the specimen main façade and the foundation slab. An auxiliary steel frame was used for fixing the displacement transducers (LVDT).

Table 3 lists all the sensors used in the seismic tests together with their designation, location, direction and measurement units. Table 4 lists the name, location, direction and measurement units of the six LVDTs used in the Brick and Stone House mock-ups.

\section{Seismic testing plan}

The reference seismic input motion for the challenge was taken from the N64E strong ground motion component of the February $21^{\text {st }}, 2011$, Christchurch (New Zealand) earthquake [1]. The peak values of this component are $0.48 \mathrm{~g}, 69 \mathrm{~cm} / \mathrm{s}$ and $206 \mathrm{~mm}$, respectively acceleration (PGA), velocity (PGV) and

displacement (PGD). This last value exceeds the nominal stroke of the transverse actuator meaning that the signal had to be filtered in the low frequencies range in order to allow increasing the amplitude of the seismic action without reaching the shaking table stroke limit; such frequency range was selected in a way that it would not affect the seismic response of the mock ups. Furthermore, since the 
predicted collapse of the mock ups was expected to occur at higher intensities, it was foreseen to scale up this motion by factors higher than one and therefore the other two operational limits of the shake table, PGA and PGV, could be reached.

Taking this into account, the original time signal was processed using an Infinite impulse response digital filter, a high pass Butterworth filter with 8 poles and $1 \mathrm{~Hz}$ cut-off frequency. Since the original record is quite long, the filtered signal was then cropped keeping only the intense part of the motion. The resulting reference acceleration, velocity and displacement signals are exhibited in Figure 12. These reference signals, with a total duration of around 27 seconds, have peak values of $25.8 \mathrm{~mm}$ in displacement, $23.6 \mathrm{~cm} / \mathrm{s}$ in velocity and $0.28 \mathrm{~g}$ in acceleration. Comparing these values with the nominal capacity of the transverse actuator of the LNEC 3D shake table, the direction in which the input motion would be imposed, it can be seen that this reference motion can be multiplied by amplification factors as high as three.

The testing sequence of the Brick House mock-up is presented in Table 5. Each seismic test, numbered sequentially, was carried out in order to successively approach a given scaled reference signal ( $\mathrm{X} \%$ Ref.). This means that several intermediate small steps of increasing amplitude were imposed approaching the reference signal multiplied by the indicated scale factor and were not reached in a single step. The last test carried out reached $300 \%$ of the reference signal. In between some of the seismic tests a dynamic characterization test, identified by the suffix CAT, was carried out with an artificially generated low amplitude wide frequency range $(0.1 \mathrm{~Hz}$ to $40 \mathrm{~Hz})$ random noise signal (WN) in order to identify the vibration frequencies and mode shapes as well as the modal damping of the mock ups. The seismic test sequence for the Stone House mock-up is presented in Table 6. It is quite similar to the other mock-up, the main differences being the intermediate levels carried out before the end of the test, the last nominal value approached ( $200 \%$ of the reference signal), and the number of dynamic characterization tests carried out in between.

Figure 13 shows the target (X\% Ref.) and achieved (ST) displacement and acceleration time histories for the Brick House seismic tests TEST03 , TEST06 and TEST08, corresponding to $100 \%, 200 \%$ and $300 \%$ of the reference signal. The peak acceleration and displacement values of the reference and ST seismic input signals for the same seismic tests are presented in Table 7. It can be seen that the displacement peak values of the reference and ST signals are in very much good agreement whereas the ST peak values of acceleration are above the reference seismic tests.

A better comparison between the reference and ST seismic input signals can be achieved through their pseudo velocity response spectra (PSV). Figure 14 presents the response spectra for all tests carried out on the LNEC-3D shaking table: TEST01, 02 and 03 correspond to $100 \%$ of the reference signal, TEST04, 05 and 06 to $200 \%$ of the reference signal, and TEST07 and 08 to $300 \%$ of the reference signal. It can be seen that, despite the differences in the PGA value, there is an overall good agreement between the reference and ST seismic input signals when a broad frequency range is considered, particularly the one with interest for the Brick House mock-up. In the Stone House, similar results were found. 


\section{Analysis of results}

The most relevant results obtained from the shake table tests are presented next. The signals acquired during the tests were digitally processed through the LabVIEW based software package for signal analysis LNEC-SPA [3] developed at LNEC. The analysis of the results was later performed in EXCEL with specialised worksheets also developed at LNEC.

\section{Buildings damage performance assessment}

The Brick House mock-up was extensively damaged in TEST08 $(1.27 \mathrm{~g})$ with the partial collapse of the gable top and North lateral wall, see Figure 15. The collapse sequence can be described in the following way: i) the northern part of the gable top fell in the out-of-plane direction (towards East); ii) at the same time the Northeast pier rocked without falling, and rotated around the vertical axis, while the Northwest pier was only rocking; iii) as a consequence, the lintel over the window on the North lateral wall fell vertically due to the lack of support provided by the Northwest pier; iv) ultimately, the Northwest pier rotated around the base towards West and subsequently fell out of the shake table; v) the southern part of the gable top fell in the out-of-plane direction (towards East).

The presence of a window opening in the North wall and a blind wall in the South side introduced an asymmetric dynamic behaviour that precluded a clear out-of-plane collapse mechanism of the East façade. In fact, the damages are particularly concentrated on the North side of the mock-up while the South wall remained almost intact until the end. As a consequence, two types of collapse emerged one the in-plane of the North wall and the other the out-of-plane of the gable top initially triggered by the former.

The collapse mechanism started to form at TEST05, with cracks less than $1 \mathrm{~mm}$ width near the corners of the windows. In TEST06 the previous cracks extended in length and new ones appeared, again with less than $1 \mathrm{~mm}$ width. In TEST07 the cracks continued to extend horizontally in the direction of the corners of the walls, with widths higher than $1 \mathrm{~mm}$. Figure 16 illustrates the evolution of the collapse mechanism.

Initial damage state observed in the Stone House mock-up before the seismic testing plan started. A horizontal thin crack, less than $1 \mathrm{~mm}$ in width, was visible on the South wall, right above the first layer of stones, that continues into the East wall up to the door; on the other side of the door three stones have also minor thin cracks. In the Northwest corner there is a small horizontal thin crack at the base, underneath one stone. Figure 17 illustrates the damage progression in the Stone House mock-up marked over the initial pictures (including the initial damage in cyan colour). After TEST03 there was some damage, with cracks propagating from the corners of the door and window and a horizontal one near the base of the Northeast corner. In TEST04 the damage progressed in the East façade, with large diagonal cracks propagating from the top South corner of the wall down to the mid height near the door, and also on the North side wall with the propagation of the existing cracks and the appearance of two new ones in the top Northwest corner and in the window lower West corner. In the last test, TEST05 (1.05g), the East façade developed an extensive crack pattern around the stones, 
that propagated around the corner to the North side wall, additional cracks developed in the South side wall and in the Northwest pier, and the two stones on the top Northwest corner detached and fell.

The damage sequence (Figure 18) in the last test was the following: i) the two stones on the top Northwest corner detached and fell out of the shake table due to the impulses that the large lintel stone over the window imposed on them (Figure 18a); ii) the Northwest pier rocked in-plan around diagonal cracks that formed from the lower corner of the window; iii) the Northeast corner rocked in the East-West direction, first as a single element, with a crack underneath it propagating from the lower corner of the window (Figure 18b), and later on split into two parts by diagonal cracks, one of them stabilized by the weight of the large lintel stone over the window and the other slightly rotated around the vertical axis (Figure 18c); iv) the South wall behaved like a large unique block delimited by the horizontal crack described in the initial damage and by cracks around the interlocking stones on the Southeast corner; v) the East façade rocked out-of-plane around large cracks that formed on both sides of the door, approximately horizontal near the base at mid-height on the North side (Figure 18d) and diagonal on the other side, propagating from the Southeast corner interlocking crack down to the mid height near the door; vi) the central part of the gable top delimited by the diagonal cracks formed on both sides of the lintel stone above the door rocked out-of-plane.

The Stone House mock-up reached a near collapse condition in TEST05 (1.05g), see Figure 19. Its behaviour was clearly influenced by the presence of the window on the North side and the door in the East façade. The former introduced a weakness in the plane of the North wall where the large dimensions and weight of the lintel stone played an important role in the development of the crack propagation and rocking of the Northeast corner. In the latter, the proportion of the door height relative to the wall height created a discontinuity in the wall dividing it into three parts, North, centre and South.

\section{Buildings strong motions general results}

For the Brick House mock-up were plotted the peak and RMS (Root Mean Square) ground acceleration induced on the base during each test stage, as abscissae values, and the corresponding registered peak and RMS acceleration on the 19 accelerometers that were fixed on the mock-up, as ordinate values. The graphics showing this relation are presented in Figure 20 and Figure 21, organized as follows:

- Peak and RMS values of accelerometers from the north side (window open lateral wall, weak side) in the direction perpendicular to the façade (transverse) organized from top to bottom;

- Peak and RMS values of accelerometers from the centre of the façade (gable top and four window corners) in the direction perpendicular to the façade (transverse) organized from top to bottom of the mock-up. Average peak (or RMS) values of the accelerometers placed in the two window corners at the same height were plotted;

- Peak and RMS values of accelerometers from the south side (lateral wall without openings, strong side) in the direction perpendicular to the façade (transverse) organized from top to bottom; 
- Peak and RMS values of the five accelerometers oriented in the longitudinal direction: ACC04 at the gable top; ACC17 and ACC01, both fixed to the south lateral wall, the first on the top level close to the corner with the façade and the second at the same level but at the opposite extreme of it; ACC19 and ACC06, both fixed to north lateral wall, the first at the top level close to the corner with the façade and the second at the same level but at the opposite extreme of it;

- Peak and RMS values of the accelerometer placed in the vertical direction (ACC05) on the gable top.

Three types of dynamic behaviour can be identified in Figure 20 and Figure 21. A straight line with a 1:1 slope means that the absolute accelerations are equal in the base and along the height of the mock-up, meaning a rigid body motion, whereas if the slope is higher means that there is dynamic amplification in the mock-up but still in the linear range. Finally, if there is an exponential increase of the slope with the increase of the input motion intensity, it means that the mock-up has a non-linear behaviour. Looking at Figure 20 it can be said that the dynamic behaviour of the Brick House is almost linear from TEST01 to TEST06, with a 1:1 slope with the exception of the gable top where the slope is higher denoting some linear dynamic amplification; this behaviour is more evident in the South side of the façade as it is the stiffer and stronger side. In tests TEST07 and TEST08, before collapse, there is an exponential increase of the acceleration, more evident from bottom to top of the mock-up. In these tests, the stiffer and stronger South side is still in the linear range with some dynamic amplification showing that the damage in the South wall was small as it was already mentioned.

As expected, the longitudinal and vertical peak and RMS accelerations shown in Figure 21 are much smaller than in the other direction, because there was no shake table input acceleration since it was a uniaxial test in the transverse direction. In the last stage (TEST08) the acceleration values measured are higher and are naturally related with the collapse of the mock-up.

The next figures (Figure 22 to Figure 24) present the relative displacements recorded considering the entire set of the time series acquired during the seismic testing plan. Due to the partial collapse of the Brick House mock up in the last test, TEST08, the LVDT_1_Top_central and LVDT_6_Top_North were disconnected during the test and, therefore, their records were truncated. All the other sensors measured high values when compared with the previous tests, as reported later in the comments to Figure 26. For this reason, the scale of the ordinate axis was kept small in order to be able to appreciate the evolution of the relative displacements up to TEST08. From the analysis of these figures it can be stated that there was a small sliding of the base of the façade from TEST05 to the TEST07; in the last test there was a slight movement towards inside the house, in the order of $1 / 10^{\text {th }}$ $\mathrm{mm}$. Similar observation can be made in relation to the relative displacements measured on the bottom South window corner LVDT, with permanent sliding to the inside, in the order of $1 / 4^{\text {th }} \mathrm{mm}$, and vibration amplitude higher to the outside than to the inside. The same observations can be made in relation to the LVDT in the bottom North window corner, with the exception that the final permanent sliding value is unknown because the sensor was disconnected although it is estimated higher than the bottom South window corner based on what can be seen in Figure 15. 
The relative displacement measured in the LVDT placed in the gable top does not show a relevant permanent displacement until the end of TEST06. What is clearly apparent until then is a much higher peak displacement to the outside of the mock-up, around twice the values to the inside, which clearly shows a different stiffness rotation of the brick corner interlocking arrangement to closing or opening the corner angle. During TEST07, the gable top showed a rocking behaviour, with almost symmetrical motions to the outside and the inside, and presented a final permanent displacement of around $1.0 \mathrm{~mm}$ in direction to the outside of the mock-up. These observations are consistent with the damage pattern presented in Figure 16 where a complete horizontal crack crossing the full length of the gable formed during TEST07, allowing the rocking motion.

The previous interpretation is confirmed by analysing the relative motions of the top South corner, which are only triggered in TEST07, also in a symmetrical way, thus showing the same rocking behaviour. A completely different behaviour is observed in the top North corner. A permanent sliding is evident at the beginning of all seismic tests since TEST04, only in TEST06 there is also an out-ofplane motion. In TEST07 a complex motion, probably a combination of rocking, out-of-plane and permanent sliding, is observed resulting in a relative permanent displacement of around $5 \mathrm{~mm}$. This apparently inconsistent plan asymmetric behaviour of the NE corner is probably a sign of the type of collapse this mock-up suffered, as reported previously.

The graphical representations of the permanent horizontal displacement of the façade in the perpendicular direction at the end of each stage taken from the time series of the 6 LVDTs are presented in Figure 25. The values of the permanent displacements were computed taking into account the average values of the last 100 samples ( 0.5 seconds duration) of each LVDT time series, when input seismic motions were clearly stopped. The values are plotted over the façade in the position of each measured point.

The graphics presented in Figure 26 illustrate the relation between the peak and RMS ground acceleration induced at the base of the Brick House mock-up during each test stage and the corresponding registered peak and RMS relative displacements on the 6 LVDTs that were fixed on the mock-up; the former are plotted in abscissae and the latter in ordinates. In the LVDT_1_top_central and LVDT_6_Top_North the maximum values in the last stage were calculated before they were disconnected due to the collapse of the gable top. Figure 26 is organized as follows:

- On the left, are shown the three peak and RMS values of the LVDTs that are close to the gable top in the direction perpendicular to the façade (transverse) organized from top to bottom: first, the one closer to the top of the gable; second, the one closer to the top Southeast corner; last, the one closer to the Northeast corner;

- On the right, are shown the peak and RMS values of the LVDT that are close to the base, to measure the possible sliding between the East façade and the slab foundation, and close to the bottom window corners (South and North).

From the observation of Figure 26 it can said that the peak and RMS relative displacements increase along the entire testing plan and along the height of the wall, showing dynamic amplification. The values obtained from the LVDT at the base of the wall are very small revealing that the sliding of the 
wall was minimal. At the windowsill level, the values are similar up to stage TEST07; in the last one, the North side is much higher. In the top North and South LVDTs the peak and RMS values show a sharp increase starting at stages TEST03 and TEST05 respectively. These plots confirm the observations made in the previous paragraphs when discussing the time history evolution along the entire seismic testing plan.

A similar analysis was performed for the Stone House mock-up. First, the registered peak and RMS acceleration were plotted, for the 19 accelerometers that were fixed to the mock-up as a function of the peak and RMS ground acceleration that was induced on the base during each test stage. The graphics showing this relation are presented in Figure 27 and Figure 28 and have the same layout described previously for the Brick House mock-up. Looking at Figure 27 it can be said that the Stone House shows an almost linear dynamic behaviour up to TEST03 due to the seismic loading in the transverse direction. In the last two tests, TEST04 and TEST05, there is a sharp increase in the peak acceleration values in the direction perpendicular to the façade. This increase is more evident in the accelerations measured near the Northeast corner and top of the wall that denotes the presence of a local response consistent with the building damage previously described. Interestingly, only the RMS accelerations in the Northeast corner show a similar behaviour. From the observation of Figure 28 it can be said that the peak and RMS accelerations in the longitudinal and vertical directions are much smaller as expected since there was no shake table input acceleration in those directions for all seismic testing plan. It is noteworthy the evolution of the peak and RMS accelerations registered in the sensor ACC06 placed in the free corner of the North wall. This sensor was placed in one of the two stones that detached in the last seismic test, TEST05, which were already experiencing high levels of acceleration in the previous tests.

Figure 29 to Figure 31 present the relative displacements recorded using the six LVDTs used in the Stone House mock-up considering the entire set of time series acquired during the tests. The LVDT_2_Window_South was disconnected during the last stage (TEST05), reason why its record was truncated. Again, the scale of the ordinate axis was kept small in order to be able to appreciate the evolution of the relative displacements up to TEST05. The analysis of these figures shows that:

- From TEST03 to the TEST05 there was a small sliding of the base (LVDT_4_Base_Rel). In the last test there was an increase of about $5.4 \mathrm{~mm}$;

- The relative displacement increases in the LVDT placed in the gable top (LVDT_1_Top_central) along the entire testing plan. At the end of TEST05 the relative displacement value was around $38 \mathrm{~mm}$;

- In the top level, wall North corner (LVDT_6_Top_North) it was observed an increase of the relative displacement values from TEST03. The value of the relative displacement registered in the TEST05 was around $82 \mathrm{~mm}$;

- In the top level South corner (LVDT_3_Top_South) there was a slight increase of relative displacement during the entire seismic testing plan and in the last stage the value was around $21 \mathrm{~mm}$; 
- In the windowsill level, door North side (LVDT_5_Window_North) it is visible the increase of relative displacements up to TEST03. In the last two stages was a decrease of the relative displacement and the final value was around $-10 \mathrm{~mm}$;

- In windowsill level, door South side (LVDT_2_Window_South) a small increase of the relative displacement was observed from TEST02 and TEST03, and in TEST04 there was observed a small decrease of the relative displacement. In the last test due to the collapse sensor was disconnected.

The graphical representations of the permanent displacement of the façade in the perpendicular direction at the end of each stage taken from the time series of the 6 LVDTs are presented in Figure 32. The values of the permanent displacement were computed taking into account the average values of the last 100 samples (0.5") of each LVDTs time series, when input seismic motions were clearly stopped. Values are plotted over the façade in the position of each measured point.

The graphics presented in Figure 33 illustrate the relation between the peak and RMS ground acceleration induced at the base of the Stone House mock-up during each test stage and the corresponding registered peak and RMS relative displacements on the 6 LVDTs that were fixed on the mock-up; the former are plotted in abscissae and the latter in ordinates. In the LVDT_1_top_central and LVDT_6_Top_North the maximum values in the last stage were calculated before they were disconnected due to the collapse of the gable top. Figure 33 is organized as follows:

- On the left, are shown the three peak and RMS values of the LVDTs that are close to the gable top in the direction perpendicular to the façade (transverse) organized from top to bottom: first, the one closer to the top of the gable; second, the one closer to the top Southeast corner; last, the one closer to the Northeast corner;

- On the right, are shown the peak and RMS values of the LVDT that are close to the base, to measure the possible sliding between the East façade and the slab foundation, and close to the bottom window corners (South and North).

From the observation of Figure 33 it can said that the peak and RMS relative displacement increases along the entire testing plan and along the height of the wall. The values obtained from the LVDT at the base of the wall are very small revealing that the sliding of the wall was minimal. At the windowsill level the values are similar up to TEST04; at the windowsill level, South side, the peak values are smaller. In the top North and top central LVDTs the peak and RMS values are very similar; in the last test (TEST05) the values show a considerable increase. The peak and RMS values at the South top LVDT are smaller up to TEST02 but in the last test the values return to similar to the others LVDTs located at the top.

\section{Mode shapes and natural frequencies}

The data recorded by the accelerometers during the dynamic characterization tests of the Brick House mock-up, correspond to the data obtained from input-output modal identification techniques. In order to obtain the mode shapes of the structure the LNEC-SPA Module Modal Analysis Output Only 
software was used. The frequency domain decomposition from the dynamic identification tests CAT05 to CAT09 is shown in Figure 34. The first natural frequency of the Brick House mock-up was initially around $21 \mathrm{~Hz}$ and after the entire testing plan it decreased to $9.7 \mathrm{~Hz}$, corresponding to a reduction of around $54 \%$. The mode shapes were evaluated only for three dynamic characterization tests:

- CAT05- corresponding to the characterization test at the initial state, before test sequence;

- CAT08- corresponding to the characterization test after the TEST06 with 0.78g PGA;

- CAT09- corresponding to the characterization test after the TEST07 with 0.84g PGA, before the collapse.

Figure 35 and Figure 36 present the views of Brick House mock-up mode shapes for the six first vibration frequencies for the dynamic characterizations tests CAT05 and CAT08. For the CAT09 dynamic characterization before the collapse, Figure 37, only four vibration modes were identified. The numerical correlation of the mode shape vectors of the undamaged and damaged structure can be obtained by computing the Modal Assurance Criteria (MAC) value as shown in the equation below.

$$
\operatorname{MAC}_{\mathrm{u}, \mathrm{d}}=\frac{\left|\sum_{\mathrm{i}=1}^{\mathrm{n}} \varphi_{\mathrm{i}}^{\mathrm{u}} \varphi_{\mathrm{i}}^{\mathrm{d}}\right|^{2}}{\sum_{\mathrm{i}=1}^{\mathrm{n}}\left(\varphi_{\mathrm{i}}^{\mathrm{u}}\right)^{2} \sum_{\mathrm{i}=1}^{\mathrm{n}}\left(\varphi_{\mathrm{i}}^{\mathrm{d}}\right)^{2}}
$$

where $\varphi^{\mathrm{u}}$ is the mode shape vector corresponding to the undamaged condition of the structure, $\varphi^{\mathrm{d}}$ is the mode shape vector corresponding to the damaged condition of the structure and, $n$ is the number of estimated degrees of freedom [4]. The result of this expression is a scalar value in the range of 0 and 1 and indicates the extent of correlation between the two cases. Table 8 summarizes the MAC coefficients for the mode shapes of the dynamic characterizations CAT05, CAT08 and CAT09.

The data recorded by the accelerometers during the dynamic characterization tests of the Stone House mock-up, correspond to the data obtained from input-output modal identification techniques. In order to obtain the mode shapes of the structure the LNEC-SPA Module Modal Analysis Output Only software was used. The frequency domain decomposition for dynamic identification for CAT00 to CAT03 is shown in Figure 38. The mode shapes were evaluated only of two dynamic characterization tests: CAT00 that corresponding to the characterization test at the initial state, before test sequence and CAT03 corresponding to the characterization test before the collapse. Figure 39 present the views of Stone House mock-up mode shapes for the six first vibration frequencies and for the dynamic characterization CAT00. For the CAT03, dynamic characterization before the collapse (TEST 04, $1.02 \mathrm{~g}$ ), only five vibration frequencies were identified, Figure 40 . The numerical correlation of the mode shape vectors of the undamaged and damaged structure was obtained by computing the Modal Assurance Criteria (MAC). Table 9 summarizes the MAC coefficients for the mode shapes of the dynamic characterizations CAT00 and CAT03.

\section{Main conclusions}

This paper presents the main results from the shaking table tests carried out at LNEC with two masonry mock-ups, one made with clay bricks and the other with stones. The tests were carried out in 
the scope of the workshop "Methods and challenges on the out-of-plane assessment of existing masonry buildings" organized in the framework of the $9^{\text {th }}$ International Masonry Conference, held in Guimarães in July 7, 8 and 9, 2014. The mock-ups have a $U$ shape with one façade wall and two sidewalls, with a unidirectional seismic action perpendicular to main wall. Out-of-plane failures, characteristics of existing masonry buildings were found, even if much torsion was observed at failure due to the non-symmetric transverse walls. The test results allows calibration of advanced and simplified seismic assessment tools. Finally, the main general conclusions from the seismic tests can be outlined as follows:

- The asymmetry of the walls played a major role in the seismic behaviour of the buildings;

- The North lateral wall ("windowed") triggered the Near Collapse condition of the Stone house;

- The South lateral wall ("blind") did not suffer too much damage in both houses;

- "Low level" input ground motion intensity was found to cause only damage to the façades;

- The rocking behaviour "helped" to preclude the collapse of the Stone house, whereas in the case of the Clay Brick house the slenderness helped the collapse;

- The presence of a door in the Stone house was a penalizing factor in relation to the Brick house;

- The Stone house was less seismically resistant but somehow exhibited more ductility.

\section{References}

[1] ftp://ftp.geonet.org.nz/strong/processed/Proc/2011/02 Christchurch mainshock extended pass band/Vol2/

[2] http://www.Inec.pt/LNEC/DE/NESDE/

[3] MENDES, L.; CAMPOS COSTA, A.; LNEC-SPA - Signal Processing and Analysis Tool for Civil Engineers, LNEC Report, 2007.

[4] ALLEMANG, R.J.; BROWN, D. L. - A Correlation Coefficient for Modal Vector Analysis. IMAC I, Orlando, USA, 1982. 


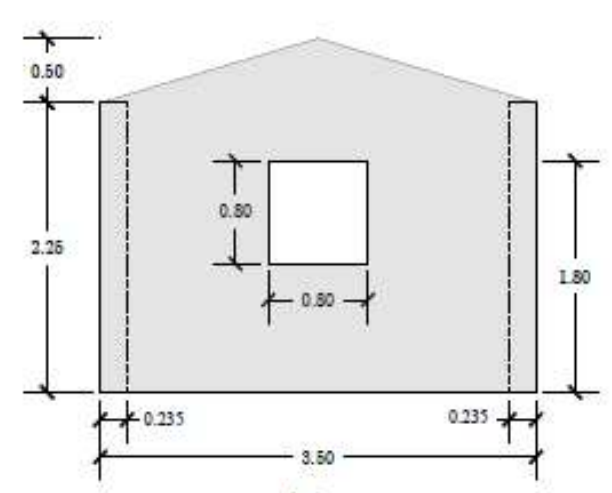

(a)

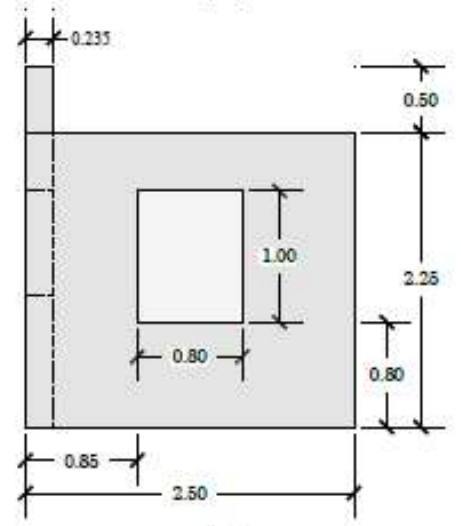

(c)

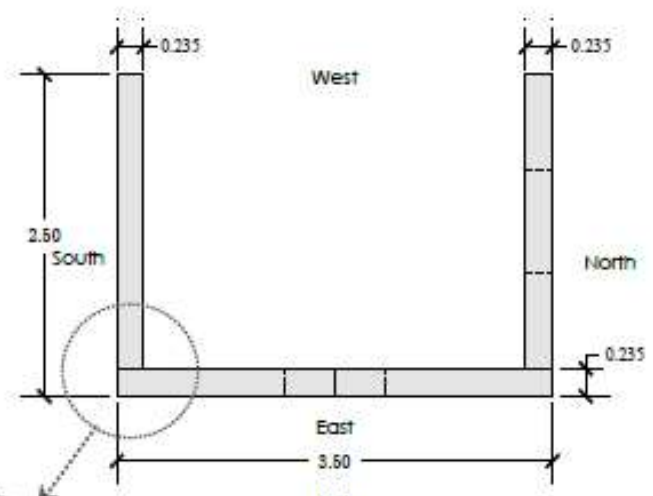

(b)

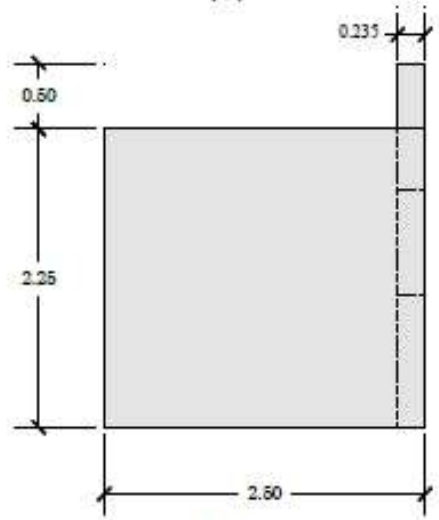

(d)

Figure 1 - Geometry of the Brick House mock-up with English bond masonry walls: a) East façade; b) Plan view; c) North elevation; d) South elevation. All dimensions in meters 


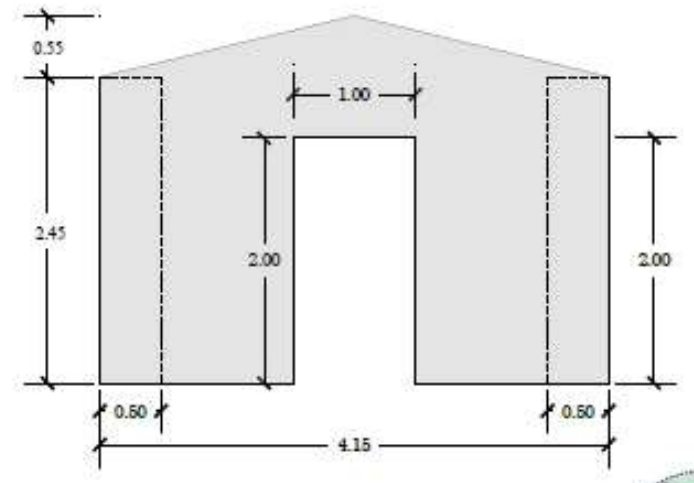

(a)

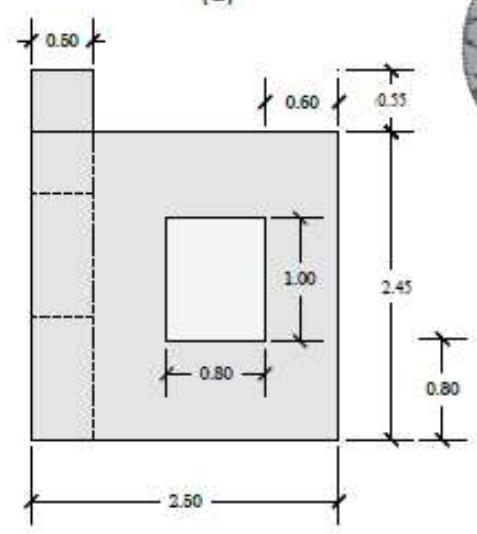

(c)

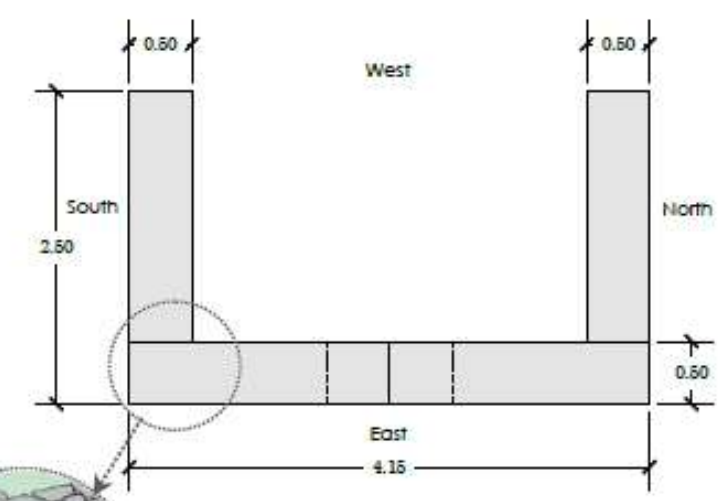

(b)

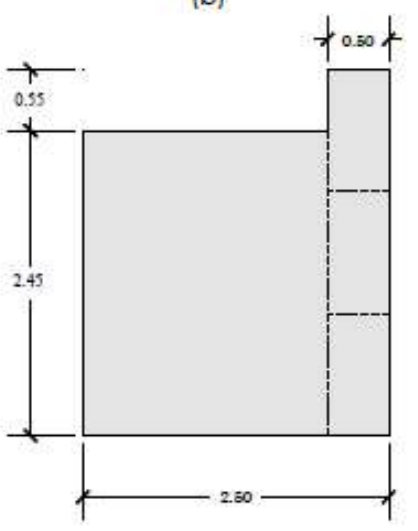

(d)

Figure 2 - Geometry of the Stone House mock-up with multiple leaves masonry walls: a) East façade; b) Plan view; c) North elevation; d) South elevation. All dimensions in meters 


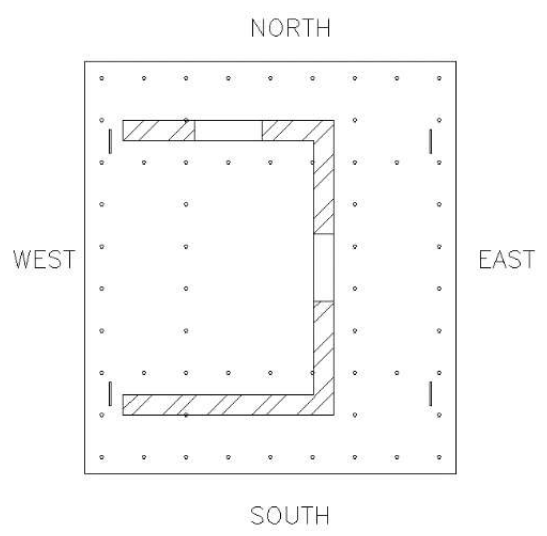

Brick House

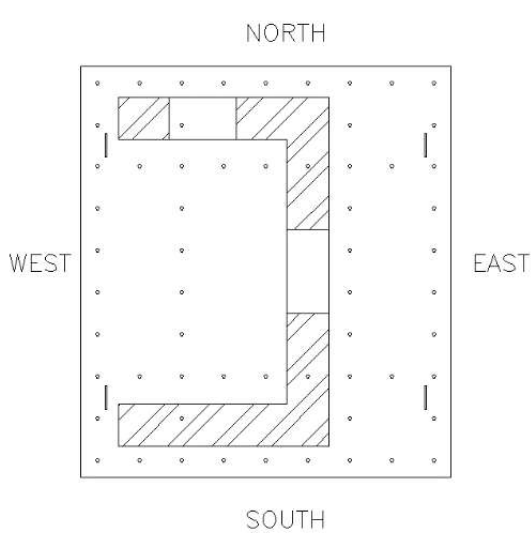

Stone House

Figure 3 - Location of the mock-ups on the reinforced concrete slabs 


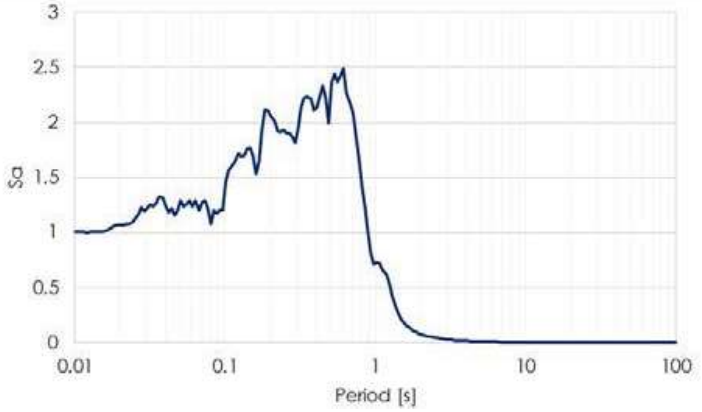

(a)

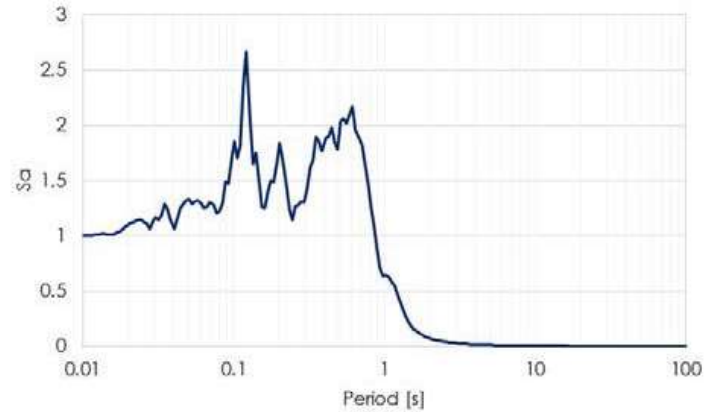

(b)

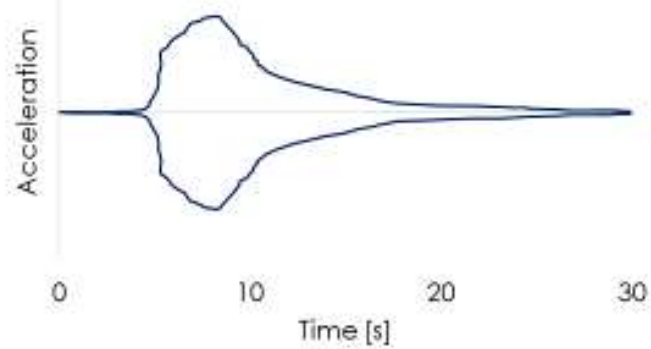

(c)

Figure 4 - Seismic action: a) Normalized acceleration response spectrum for the Brick House mock-up; b) Normalized acceleration response spectrum for the Stone House mock-up; c) Accelerogram envelope 

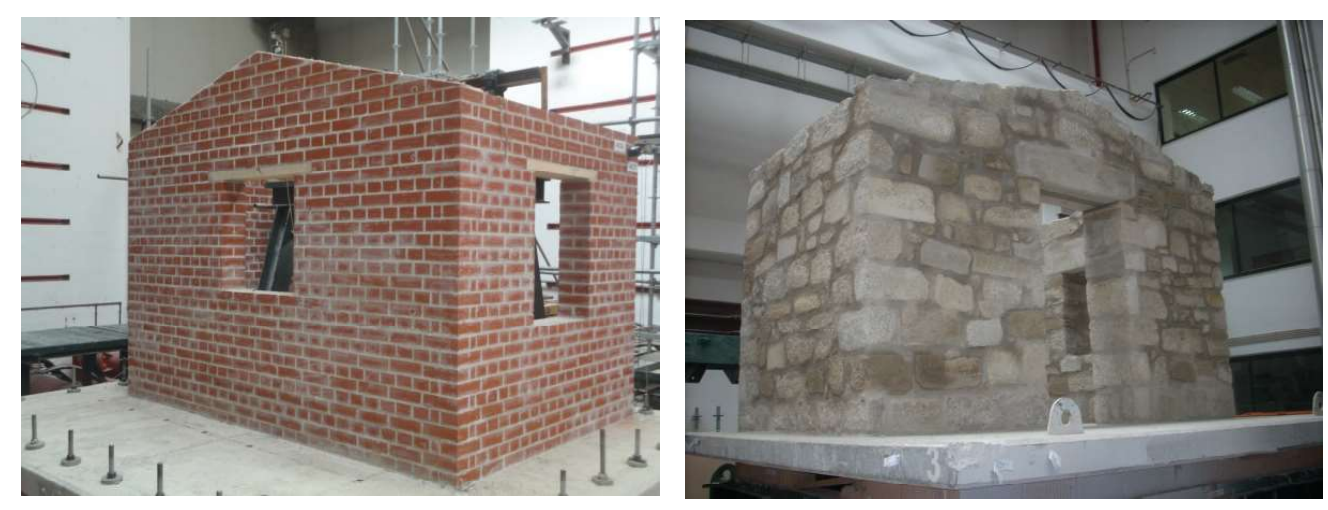

Figure 5 - General view of the mock-ups 


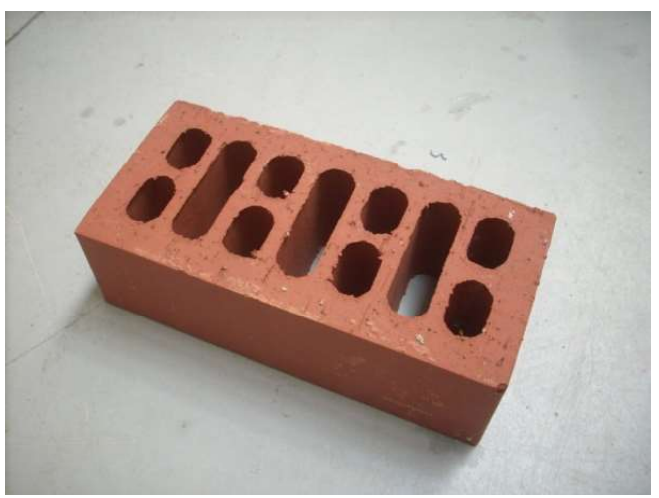

Figure 6 - View of a sample of the clay bricks used in the construction of the Brick House 


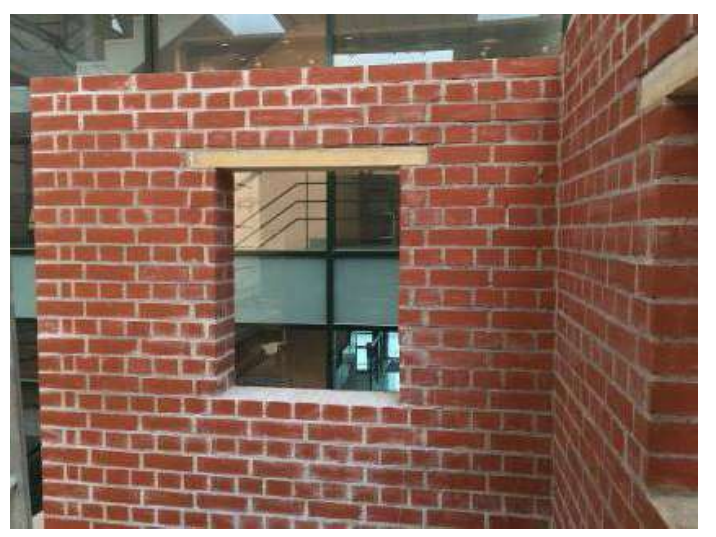

a) View of the window

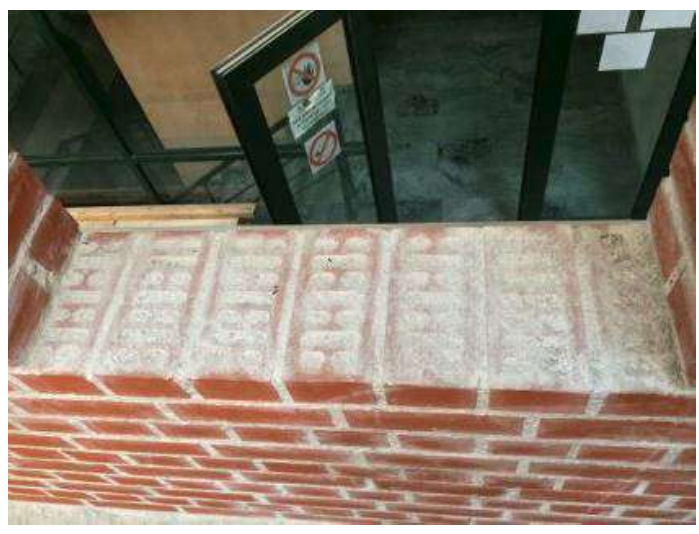

b) Detail of the window parapet

Figure 7 - Window on the North wall 


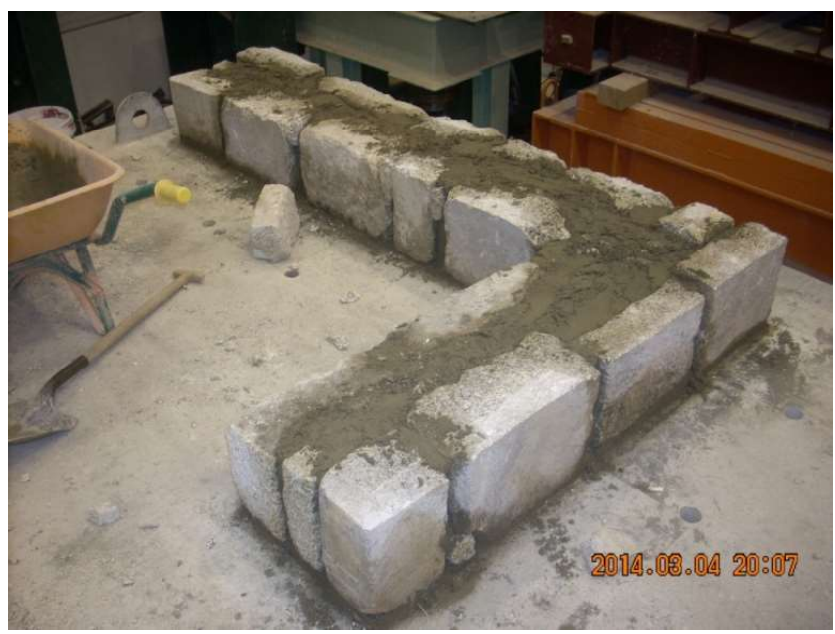

Figure 8 - Laying of the first course of stones on the East and North sides 


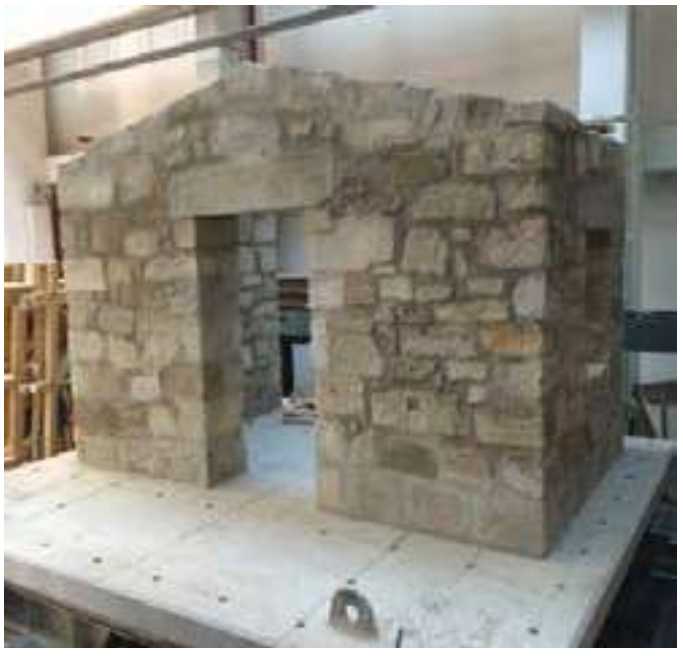

a) East wall seen from the outside

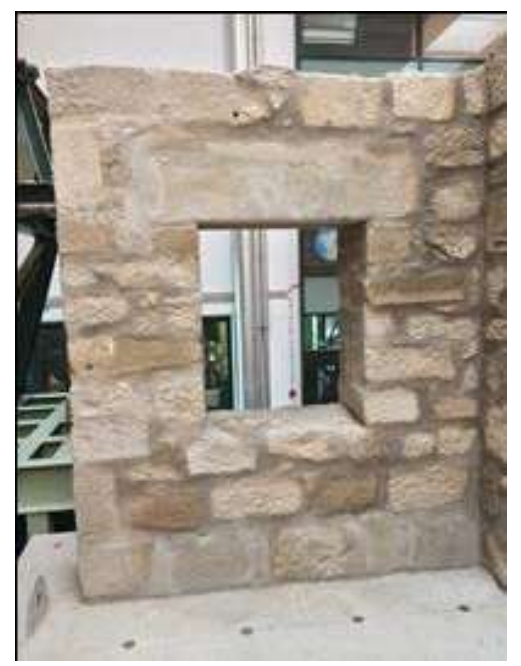

b) North wall seen from the inside

Figure 9 - View of the Stone House after the construction was finished 


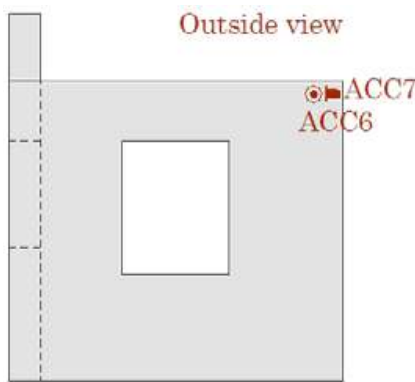

North wall

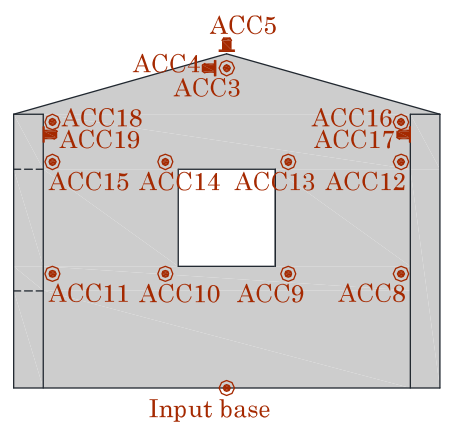

East façade, inside view

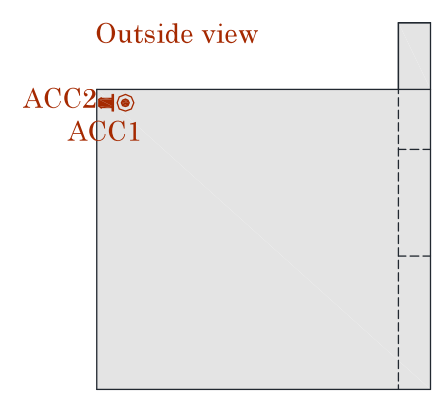

South wall

Figure 10 - Accelerometers for measuring absolute accelerations (only the Brick House mock-up is shown). 


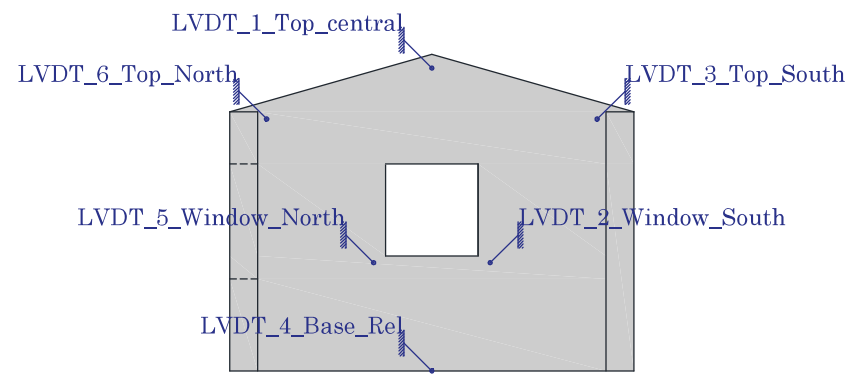

Figure 11 - Setup of LVDTs for measuring relative out-of-plane displacements of the façades of the mock-ups 

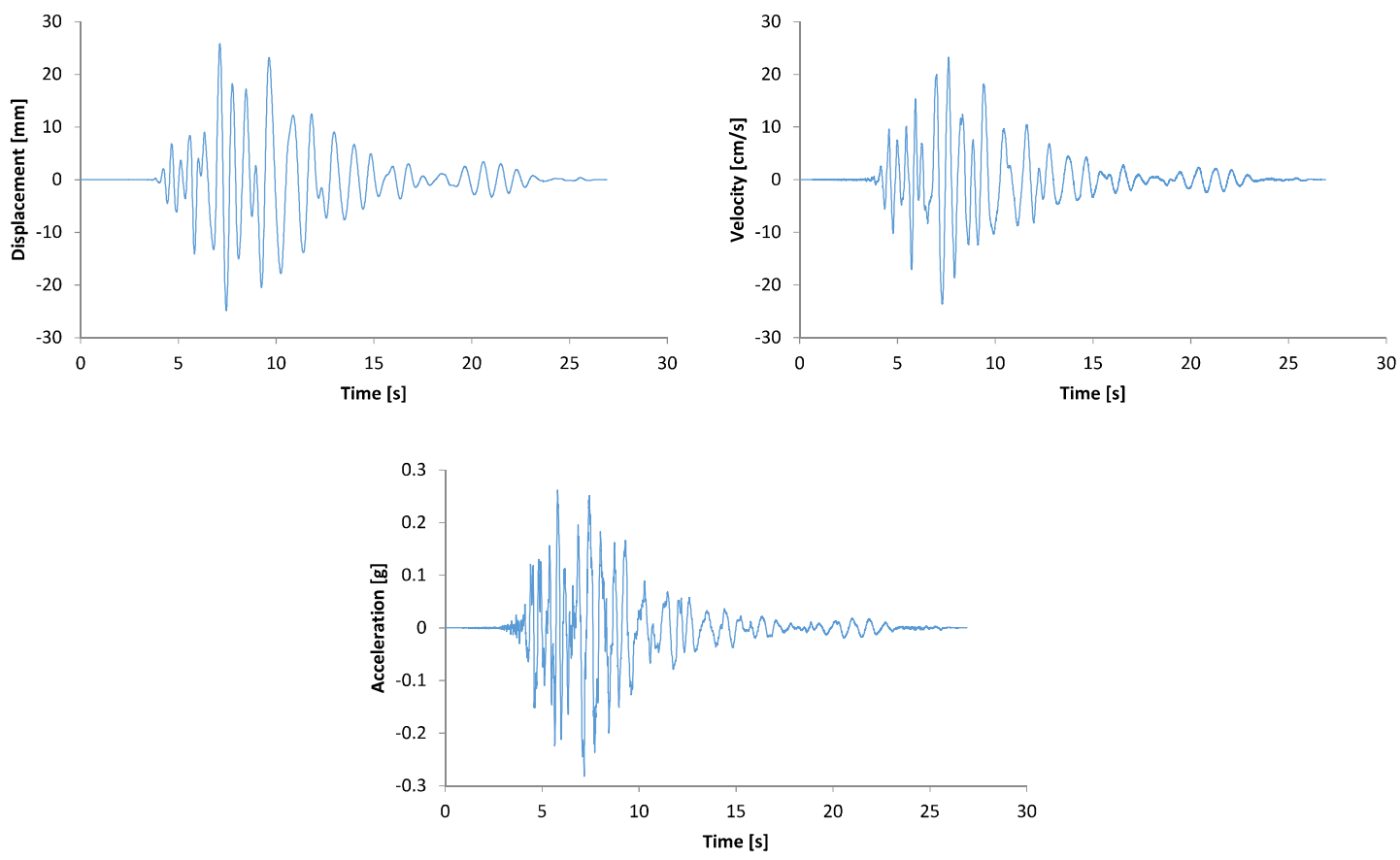

Figure 12 - Reference seismic input motions (displacement, velocity and acceleration) 

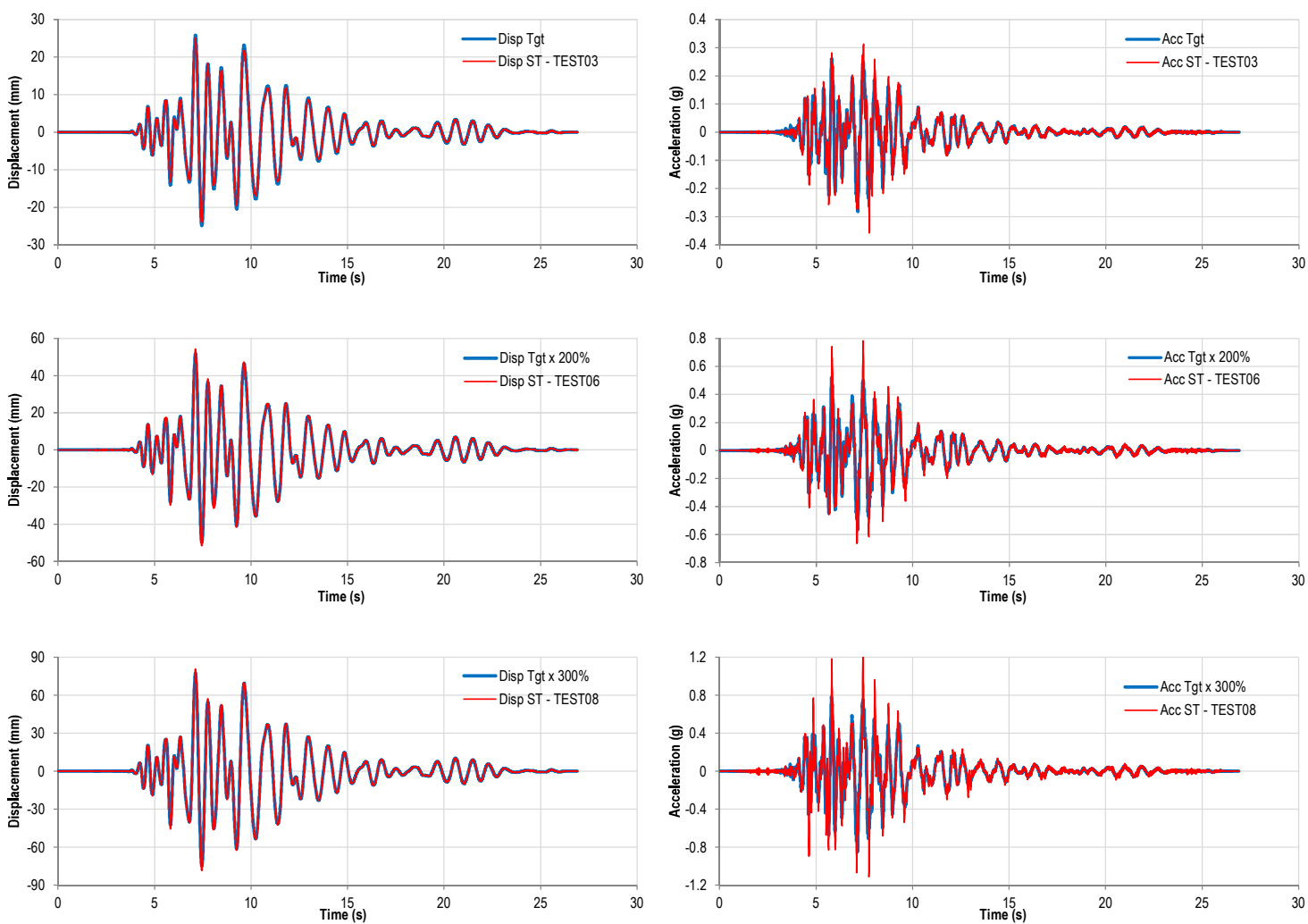

Figure 13 - Target and achieved displacement (left) and acceleration (right) time histories for tests TEST03, TEST06 and TEST08 (Brick House) 

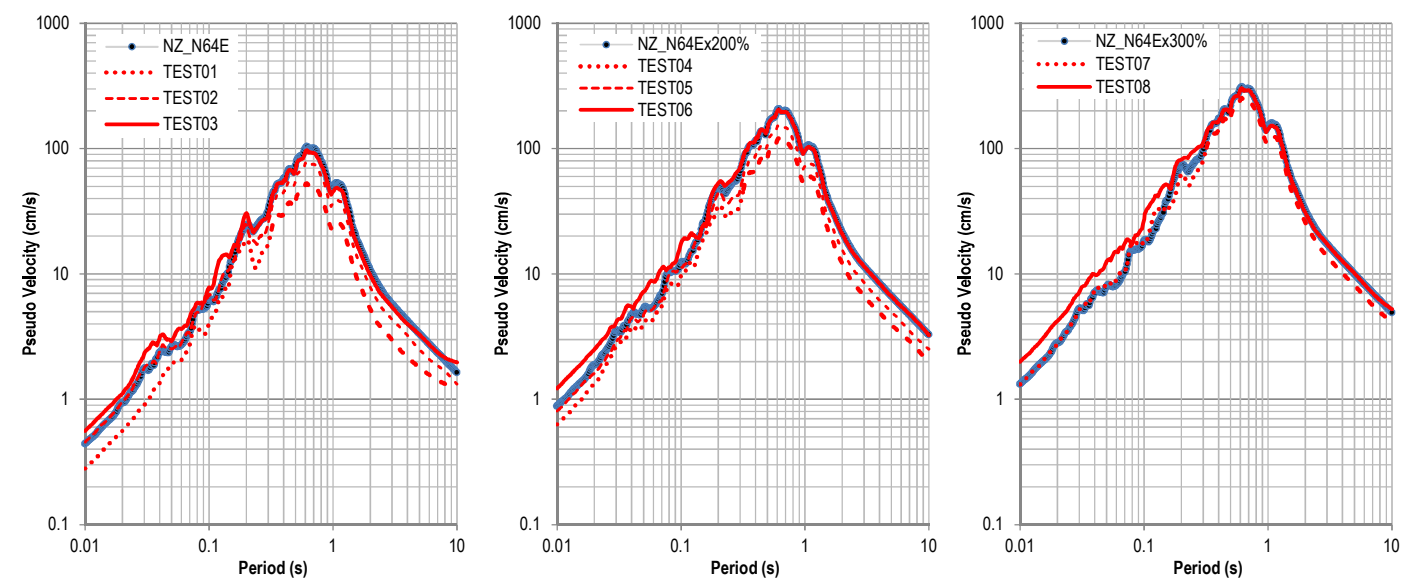

Figure 14 - Target and achieved PSV response spectra for the Brick House mock-up 


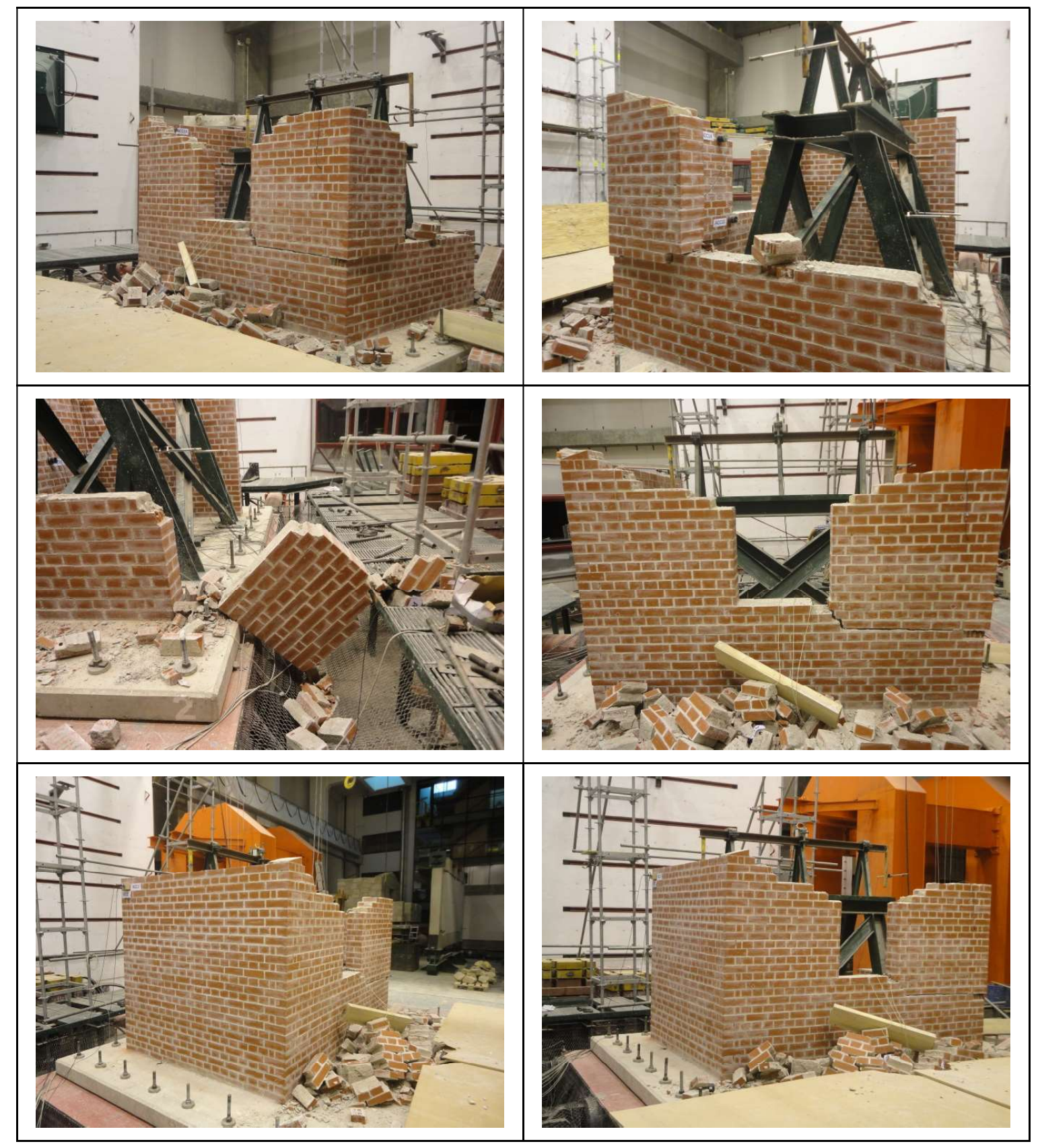

Figure 15 - Final damage state on the Brick House 


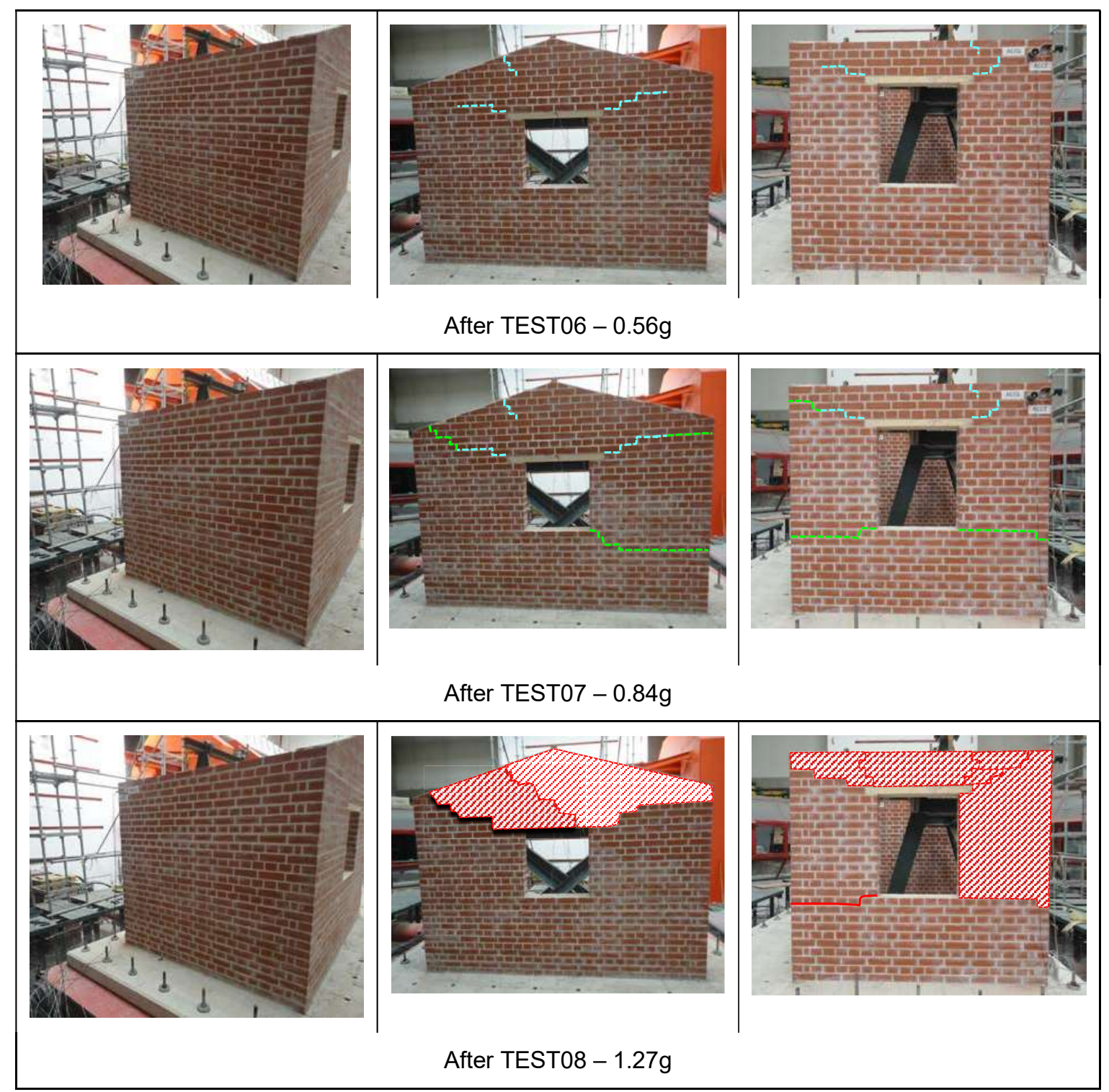

Figure 16 - Damage progression of the Brick House (left to right: South sidewall, East façade, North sidewall) 


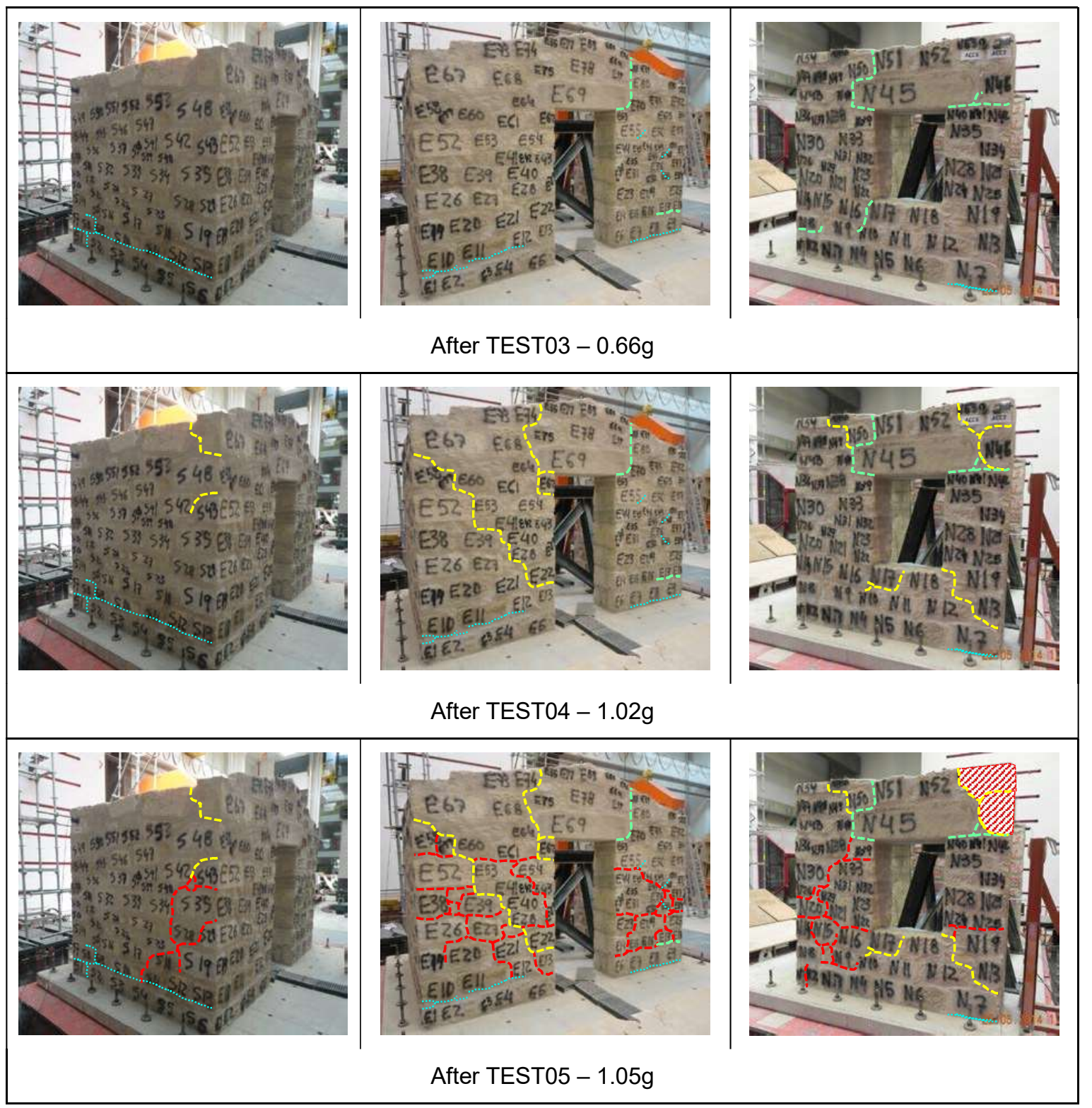

Figure 17 - Damage progression of the Stone House (left to right: South sidewall, East façade, North sidewall) 


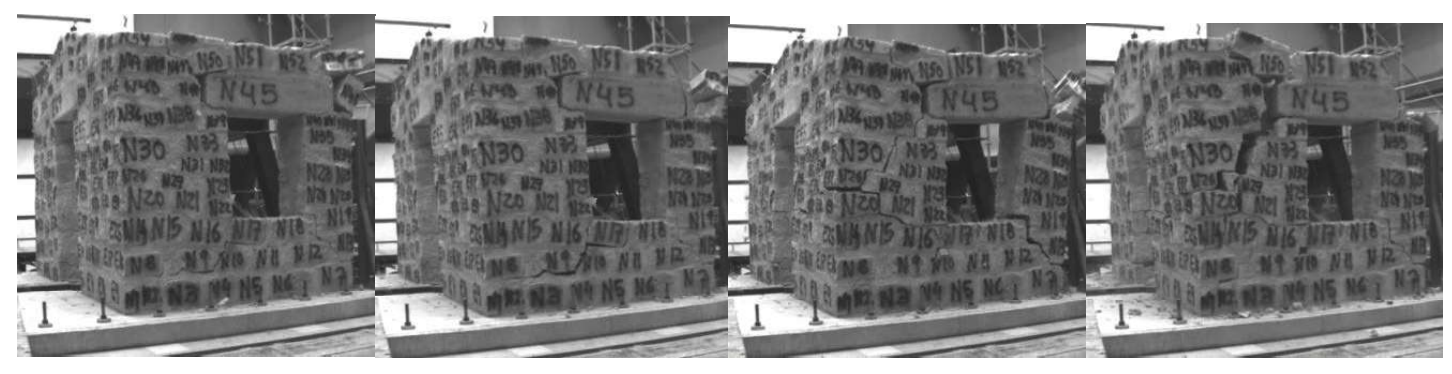

Figure 18 - Still images taken from the Stone House mock-up last test video recording (from left to right: a, b, c, d) 


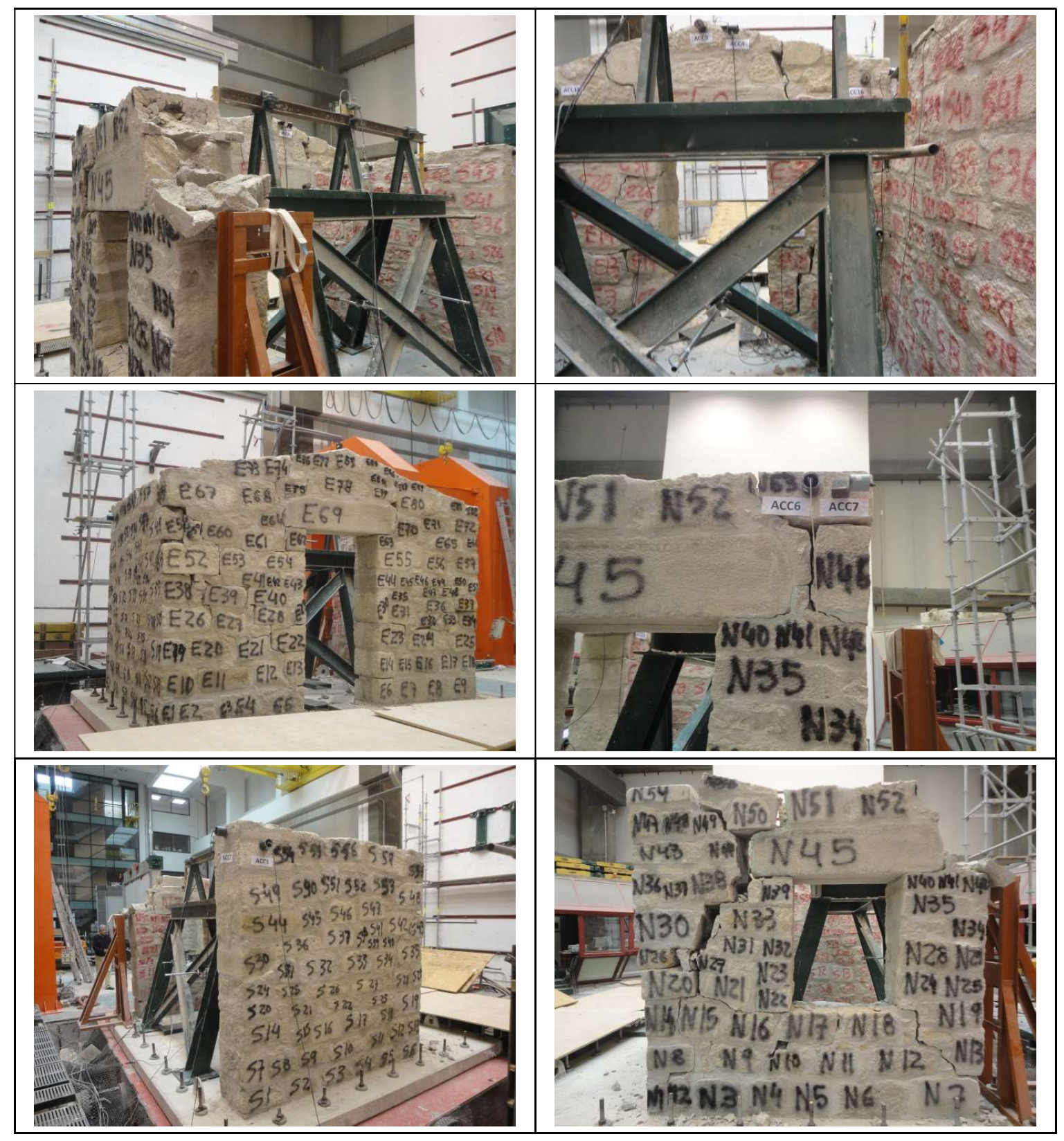

Figure 19 - Final damage state on the Stone House 

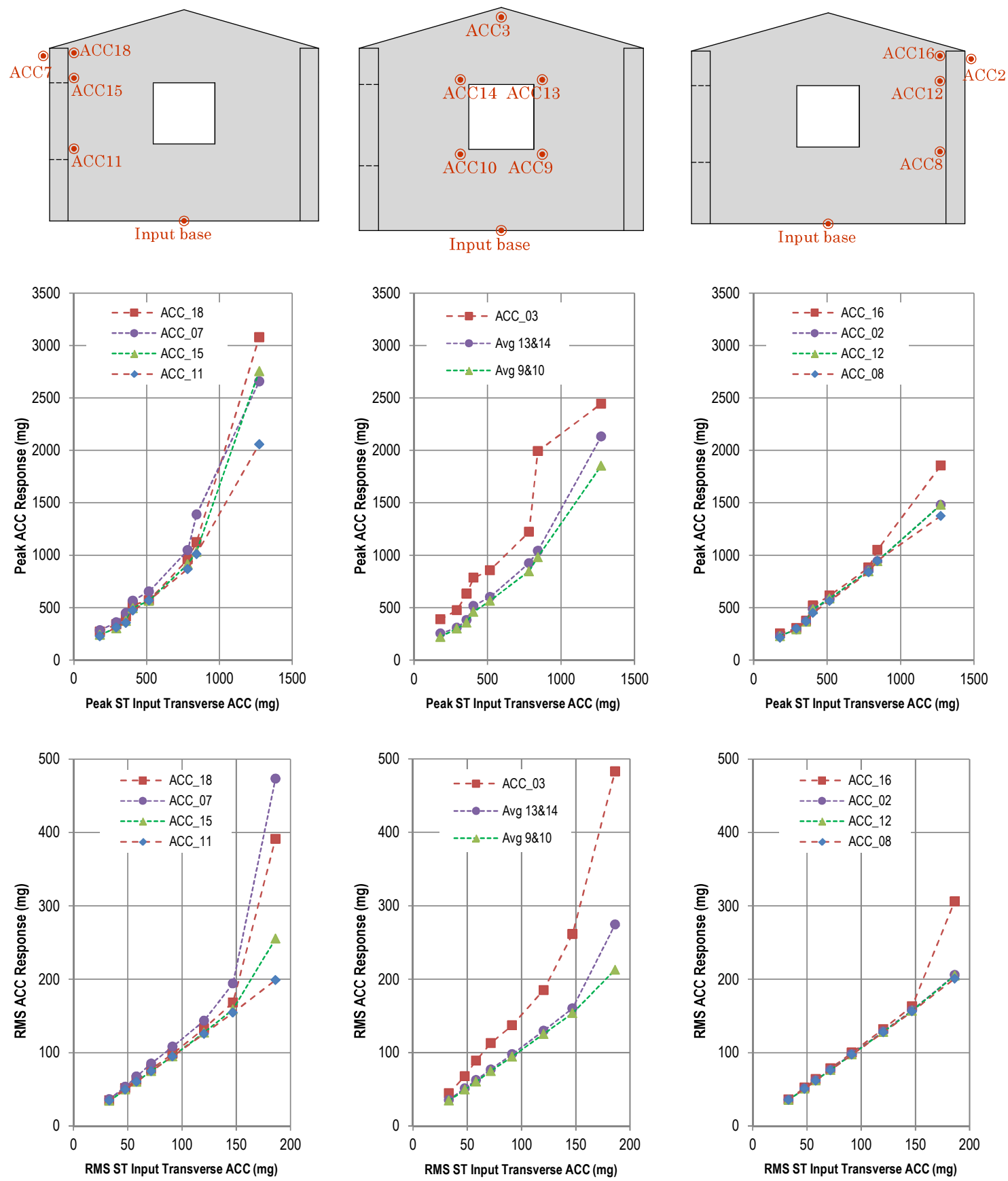

Figure 20 - Peak and RMS acceleration response for the Brick House in the transverse direction 

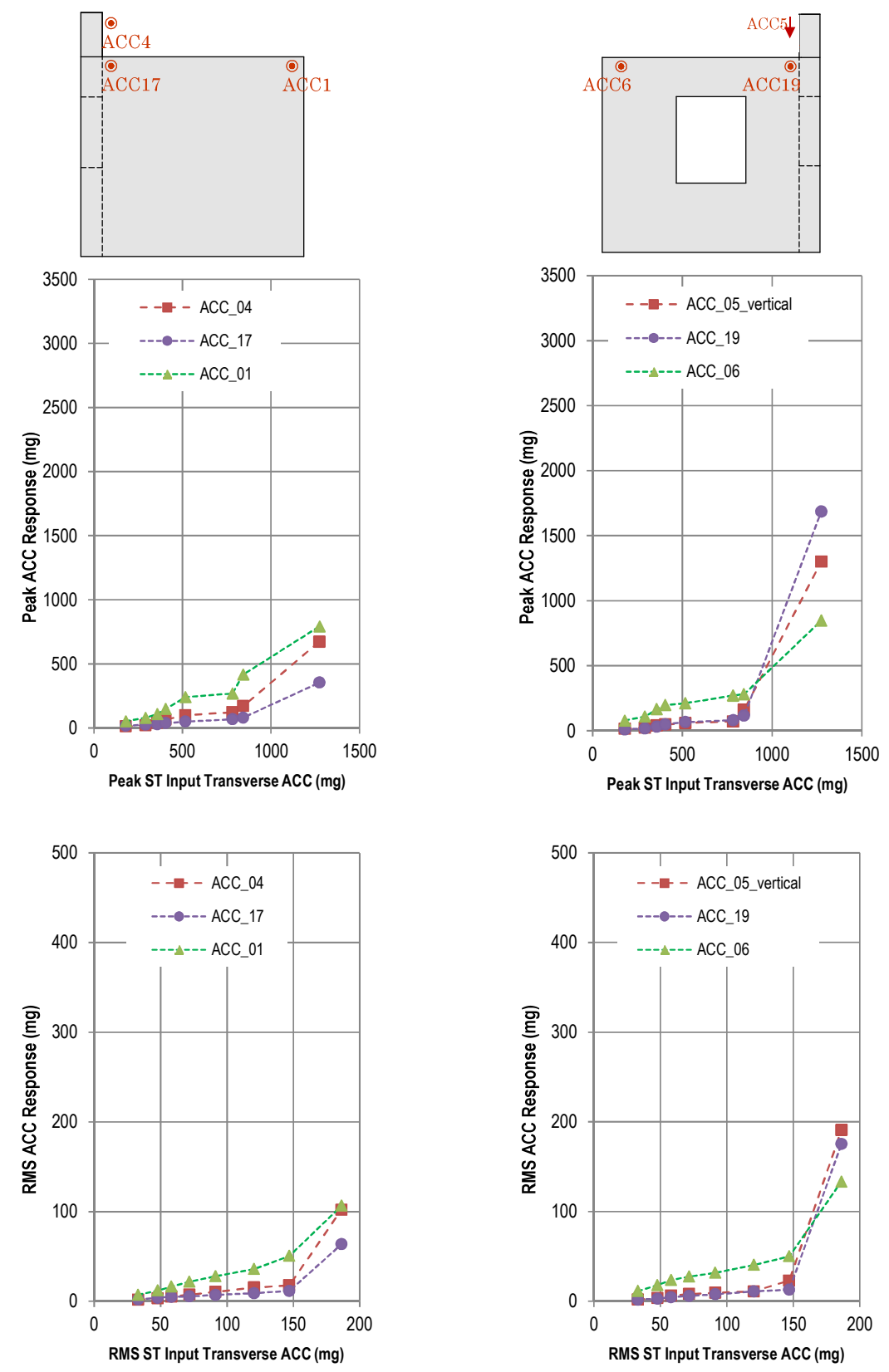

Figure 21 - Peak and RMS acceleration response for the Brick House in the longitudinal and vertical directions 

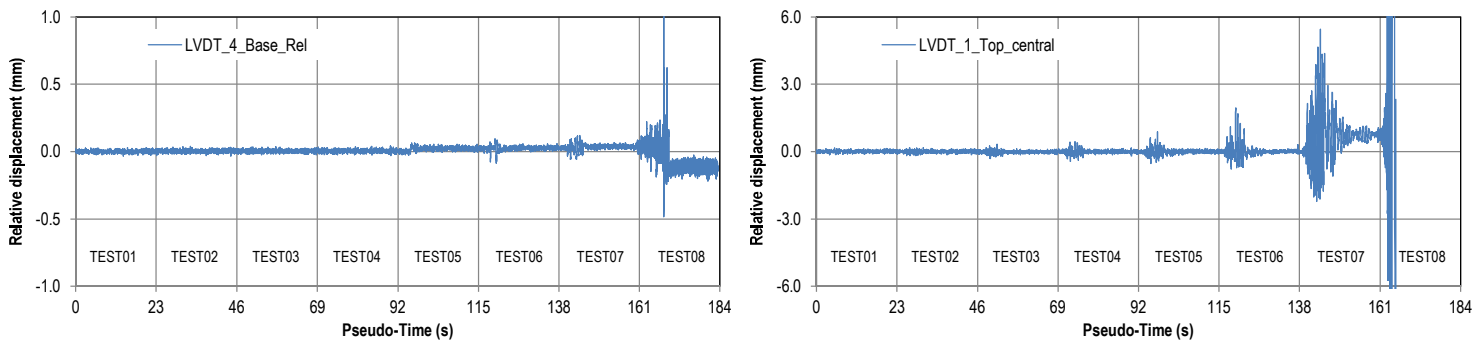

Figure 22 - Relative displacement recorded during the Brick House seismic testing plan, channels LVDT_4_Base_Rel (left) and LVDT_1_Top_central (right) 

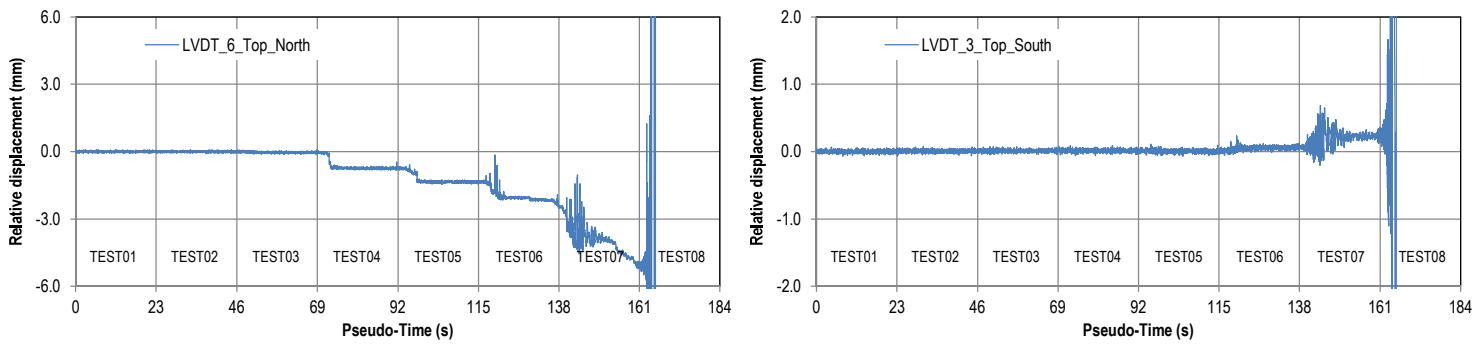

Figure 23 - Relative displacement recorded during Brick House the seismic testing plan, channels LVDT_6_Top_North (left) and LVDT_3_Top_South (right) 

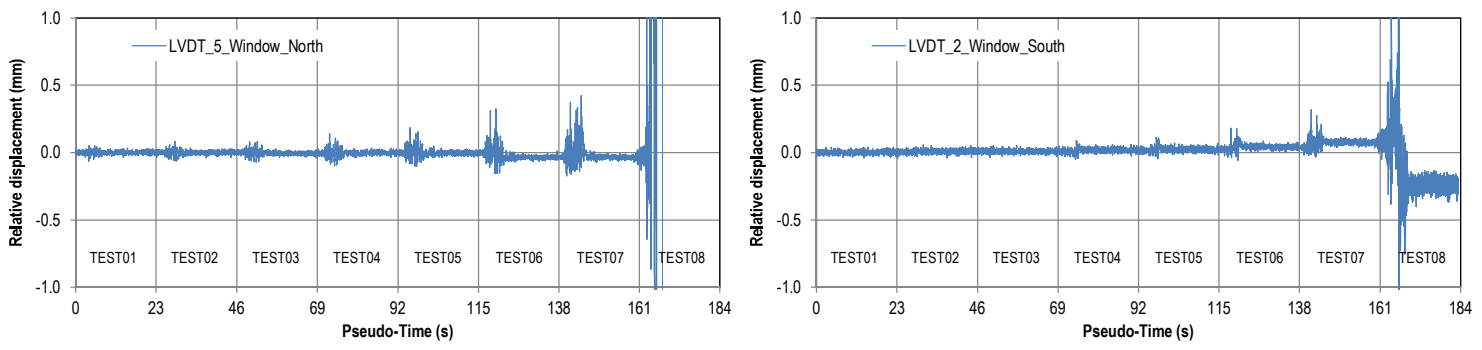

Figure 24 - Relative displacement recorded during Brick House the seismic testing plan, channels LVDT_5_Window_North (left) and LVDT_2_Window_South (right) 

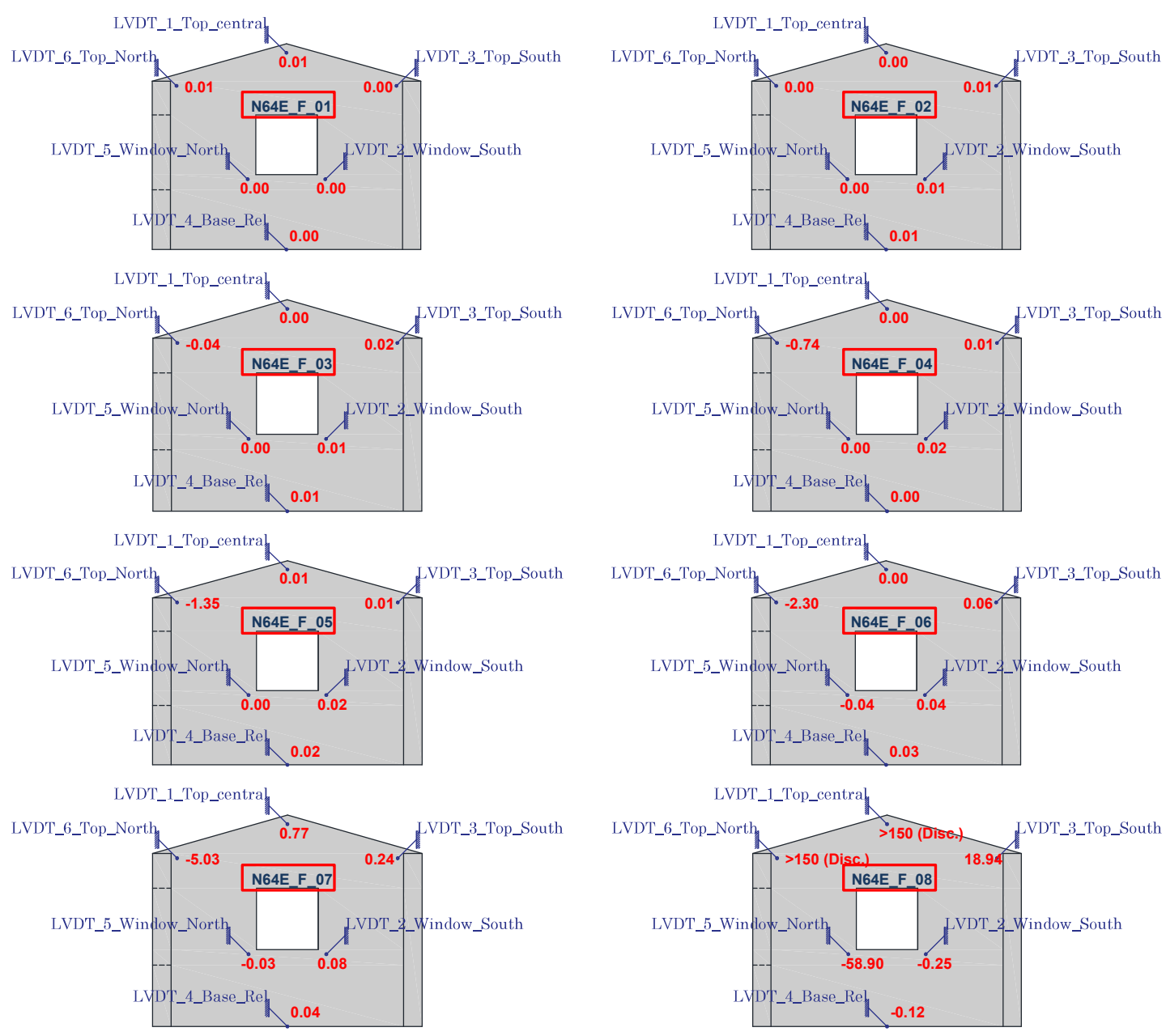

Figure 25 - Final permanent horizontal displacements in the Brick House 

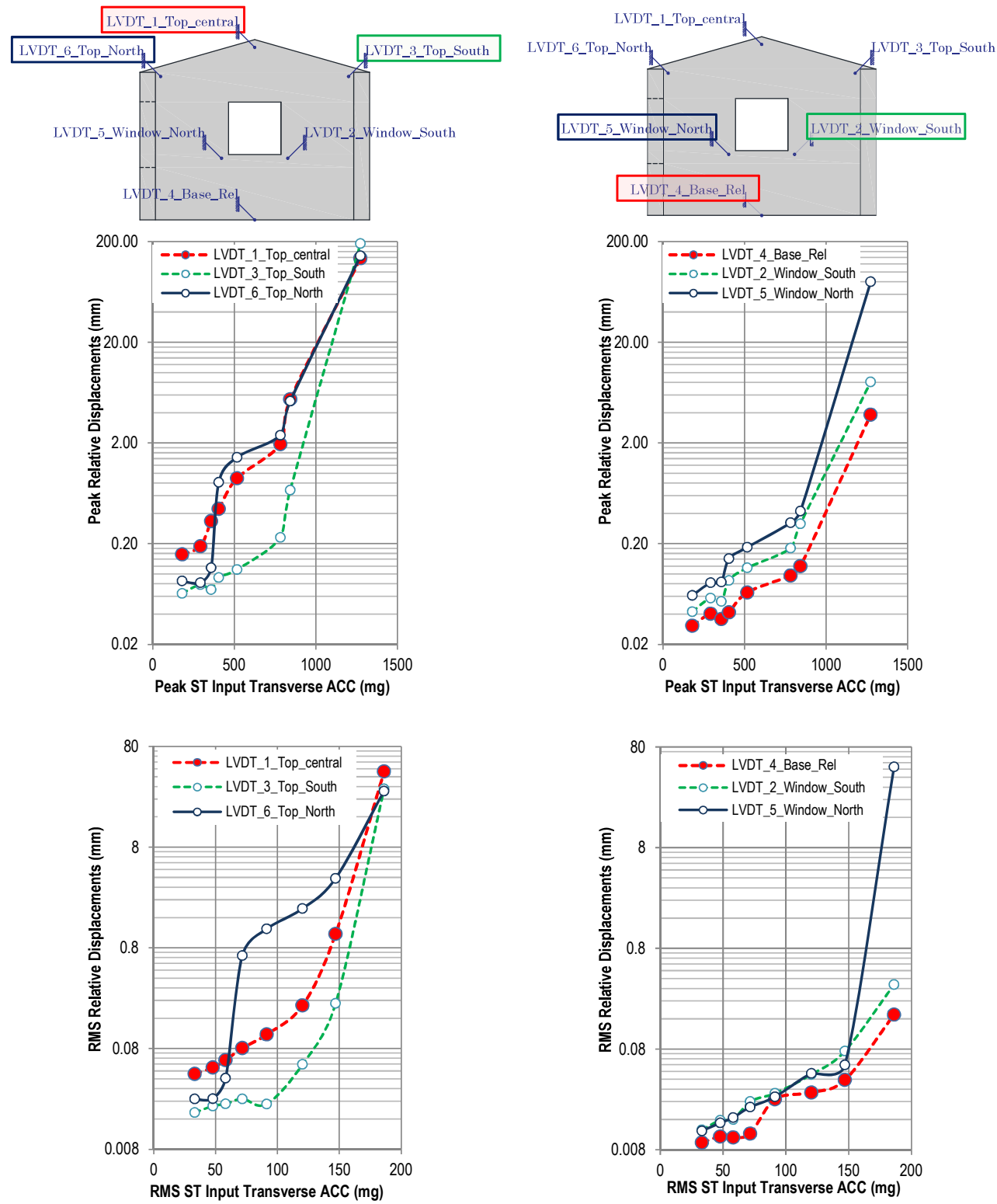

Figure 26 - Peak and RMS relative displacement for the Brick House 

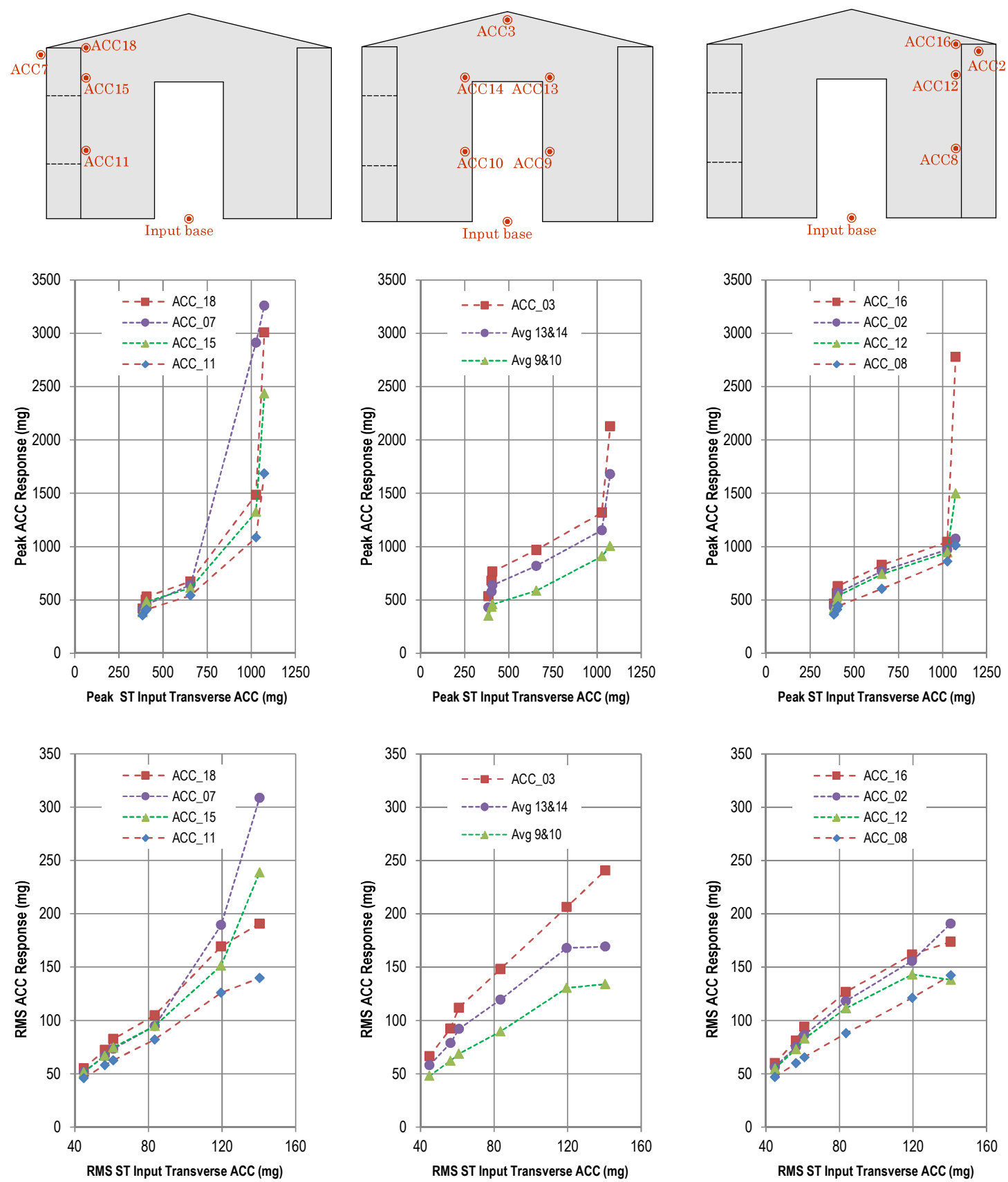

Figure 27 - Peak and RMS acceleration response for the Stone House in the transverse direction 

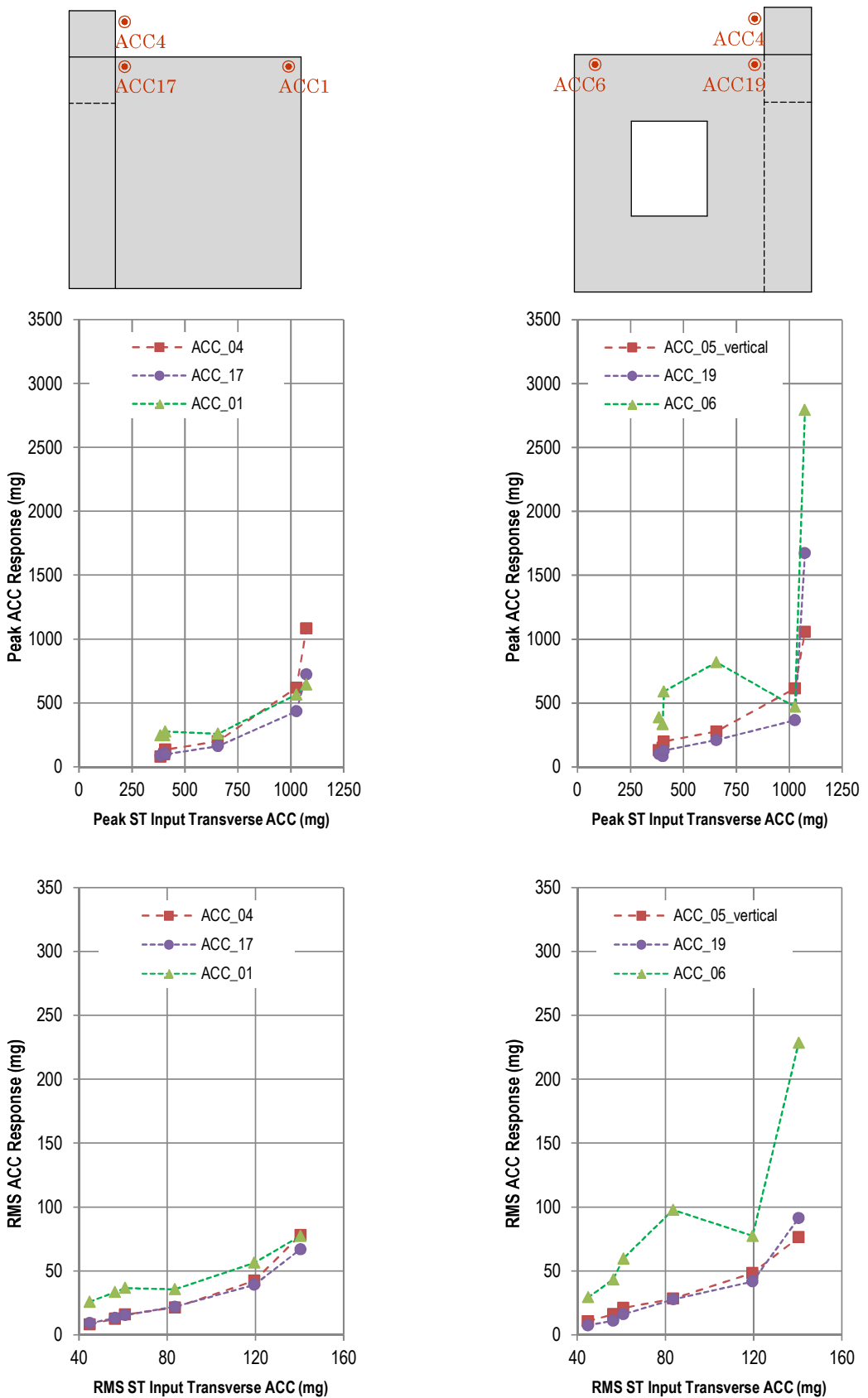

Figure 28 - Peak and RMS acceleration response for the Stone House in the longitudinal and vertical directions 

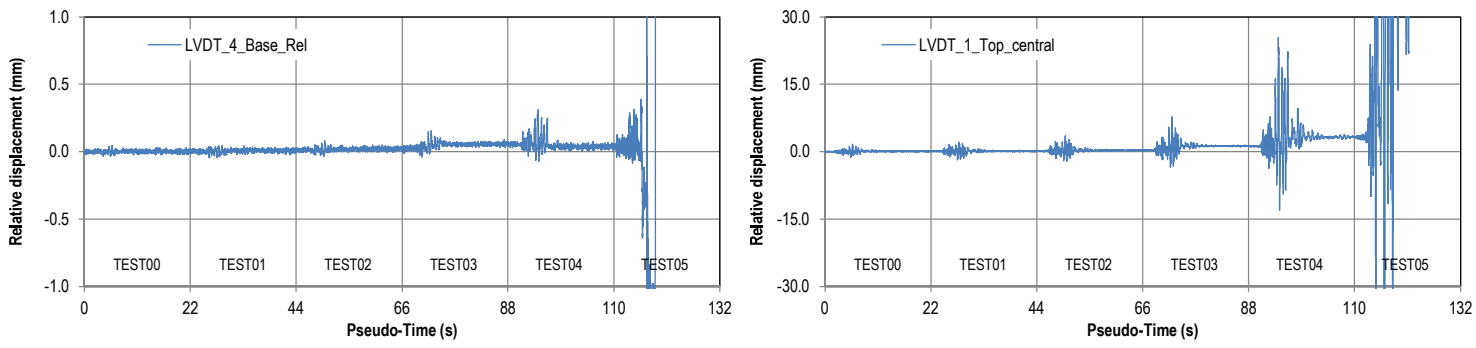

Figure 29 - Relative displacement recorded during the Stone House seismic testing plan, channels LVDT_4_Base_Rel (left) and LVDT_1_Top_central (right) 

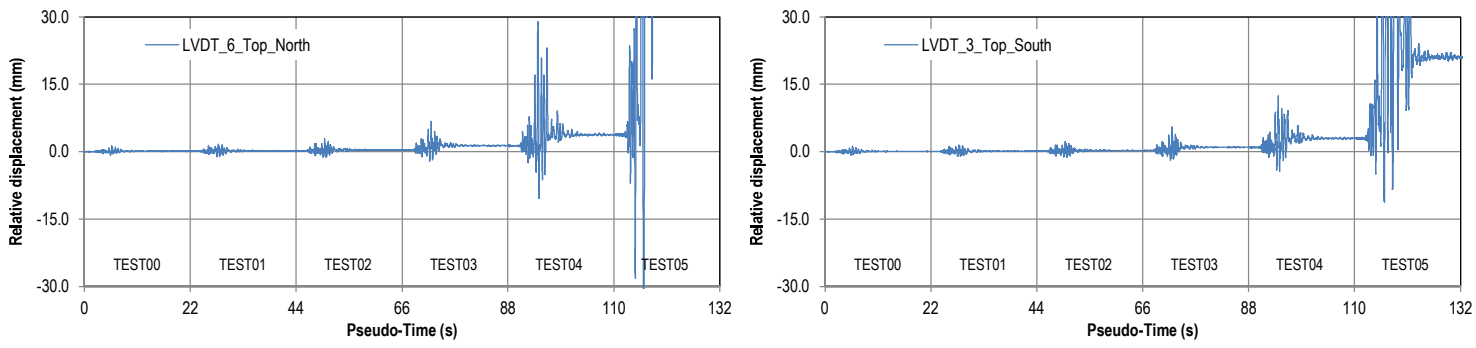

Figure 30 - Relative displacement recorded during the Stone House seismic testing plan, channels LVDT_6_Top_North (left) and LVDT_3_Top_South (right) 

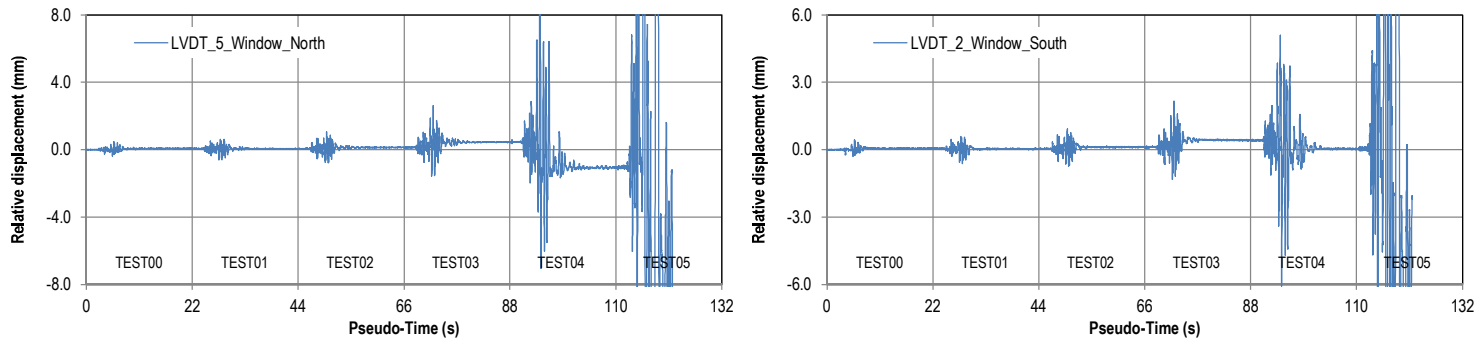

Figure 31 - Relative displacement recorded during the Stone House seismic testing plan, channels LVDT_5_Window_North (left) and LVDT_2_Window_South (right) 

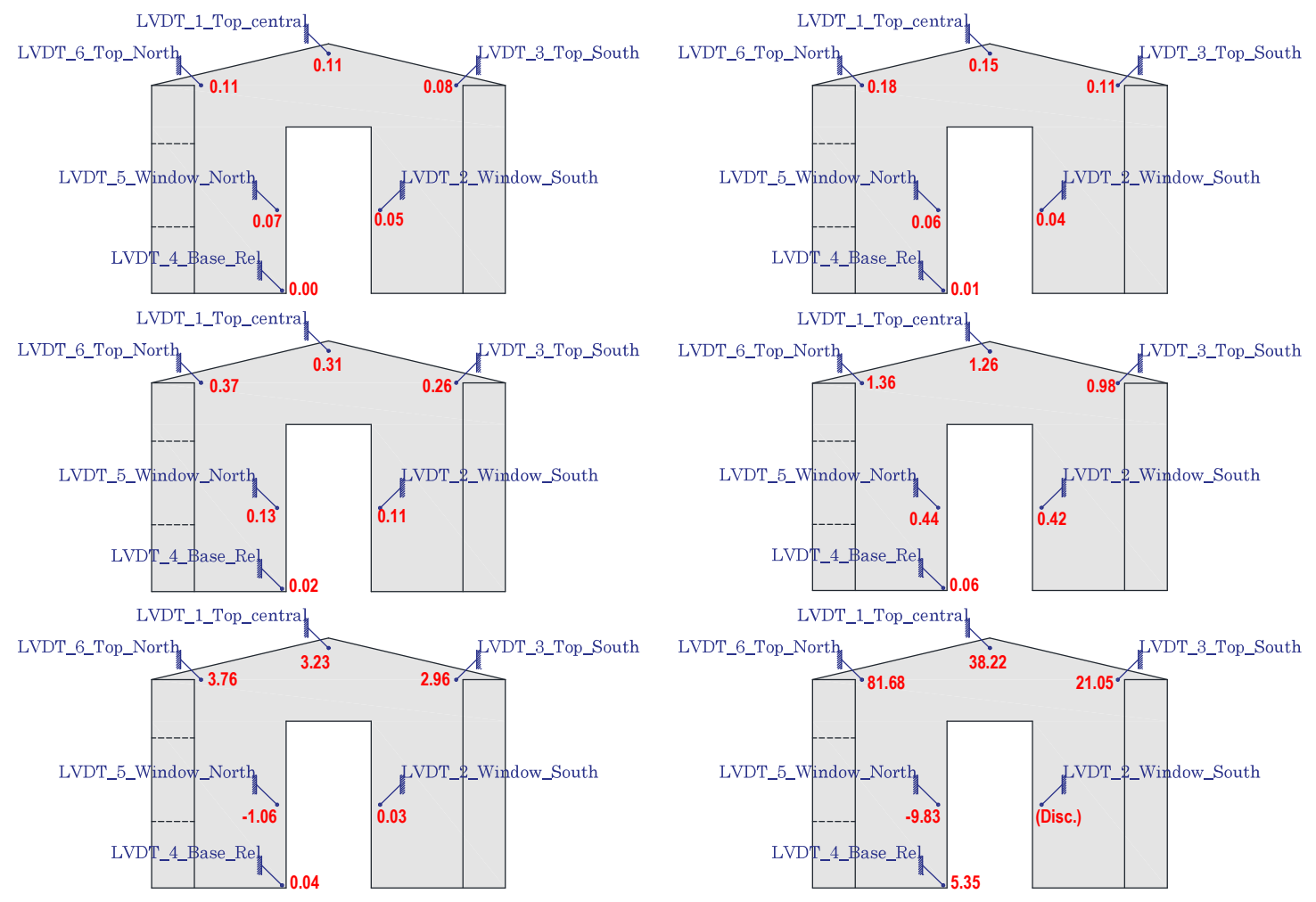

Figure 32 - Final permanent relative displacements for the Stone House 

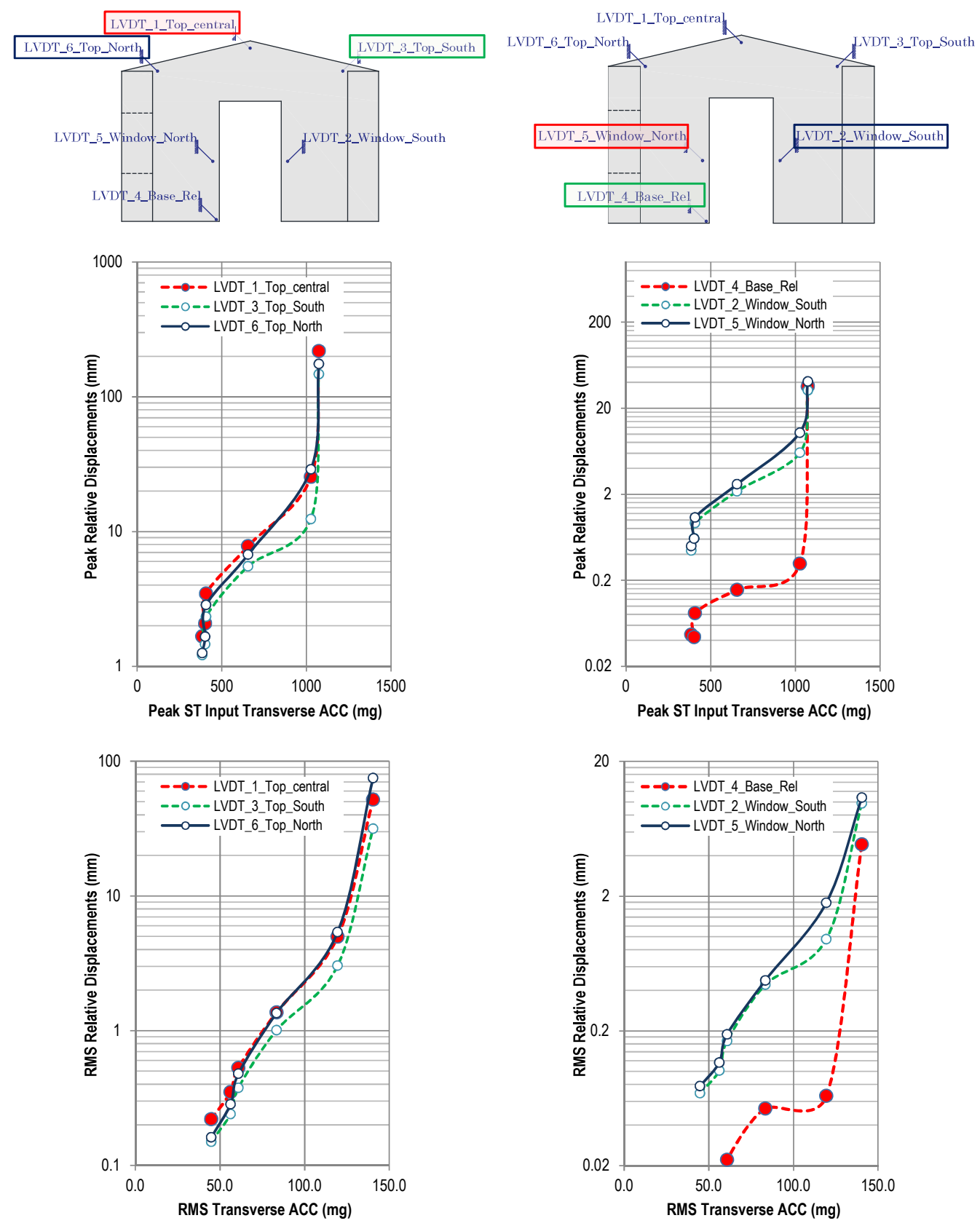

Figure 33 - Maximum and RMS relative displacement for the Stone House 


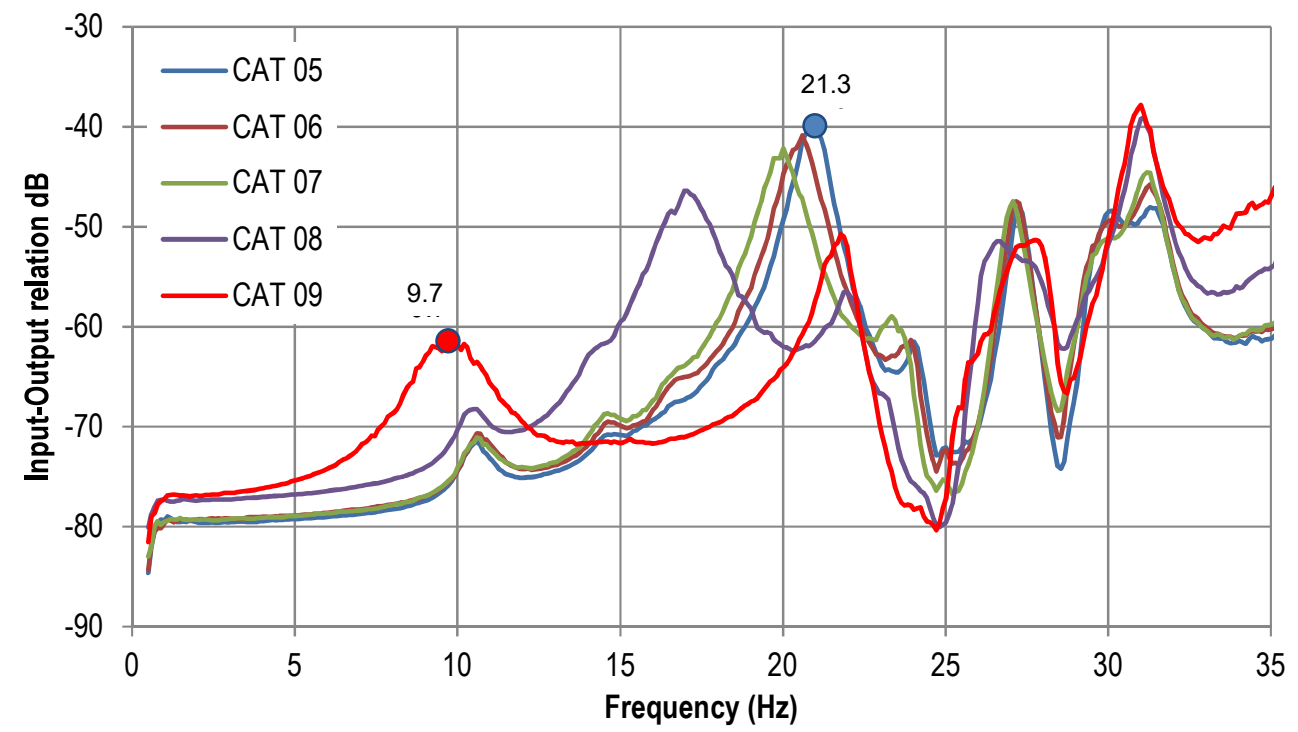

Figure 34 - Frequency domain decomposition for all dynamic identification tests of the Brick House mock-up 


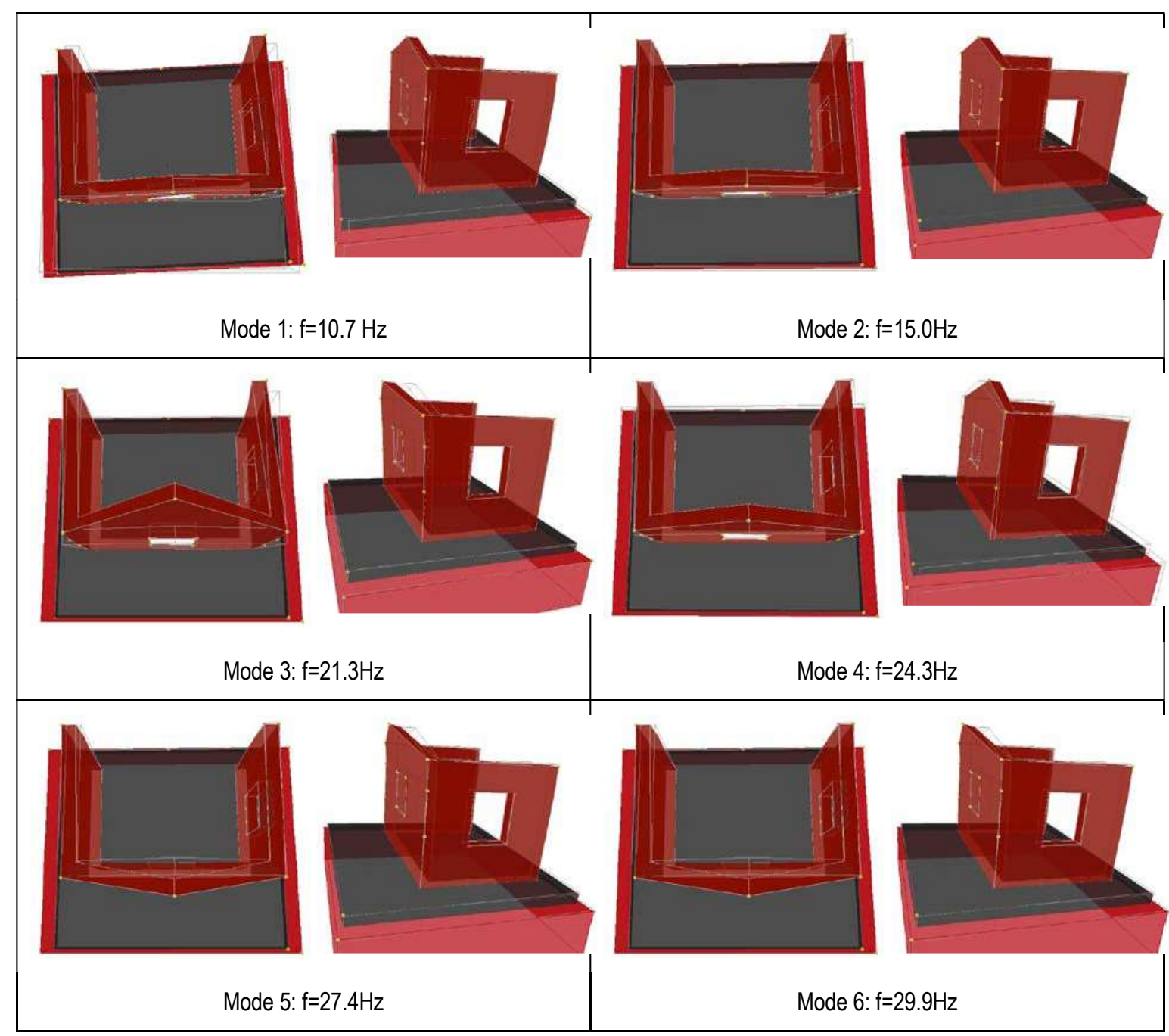

Figure 35 - Mode shapes for CAT05 of the Brick House mock-up 


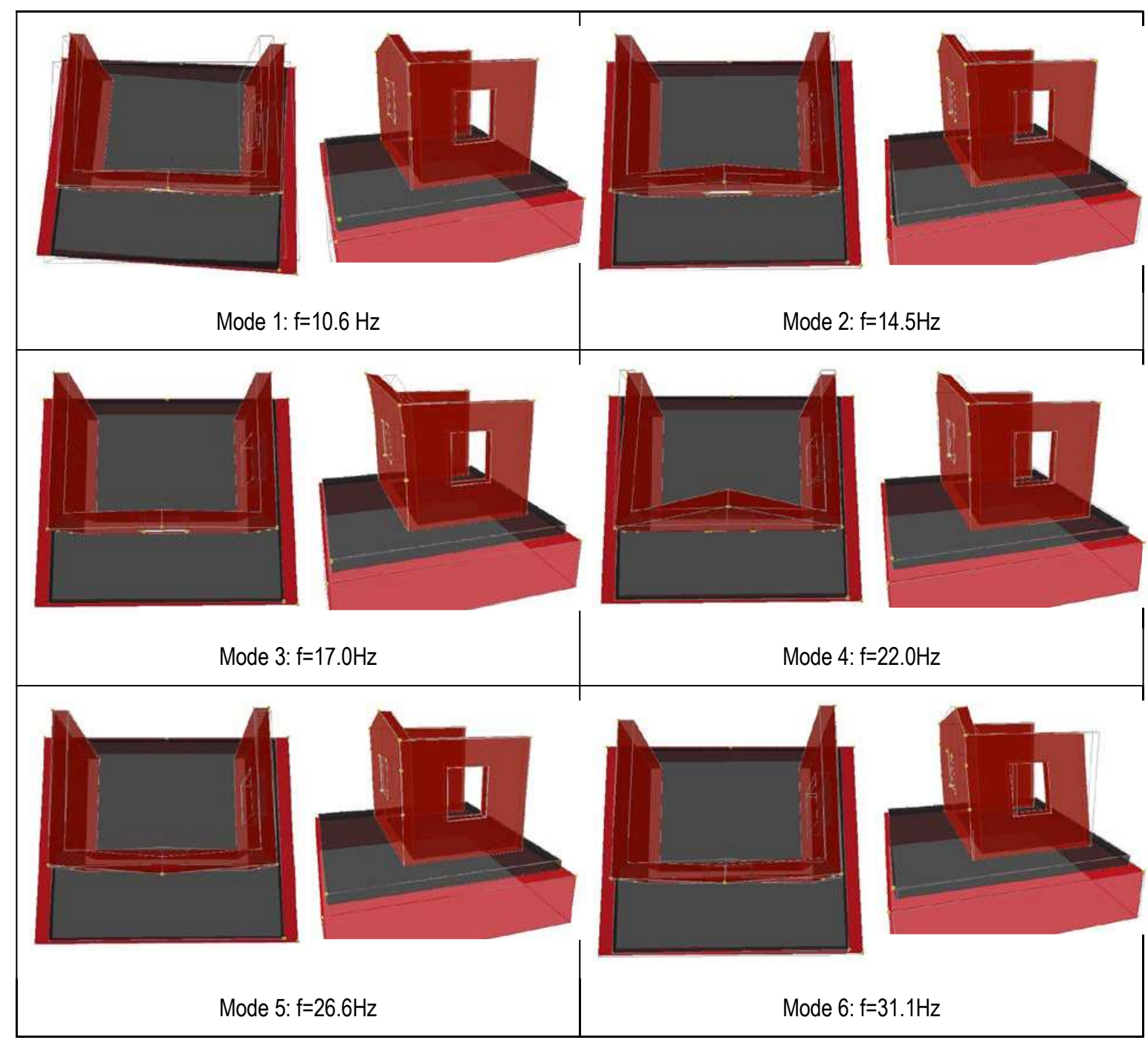

Figure 36 - Mode shapes for CAT08 of the Brick House mock-up 


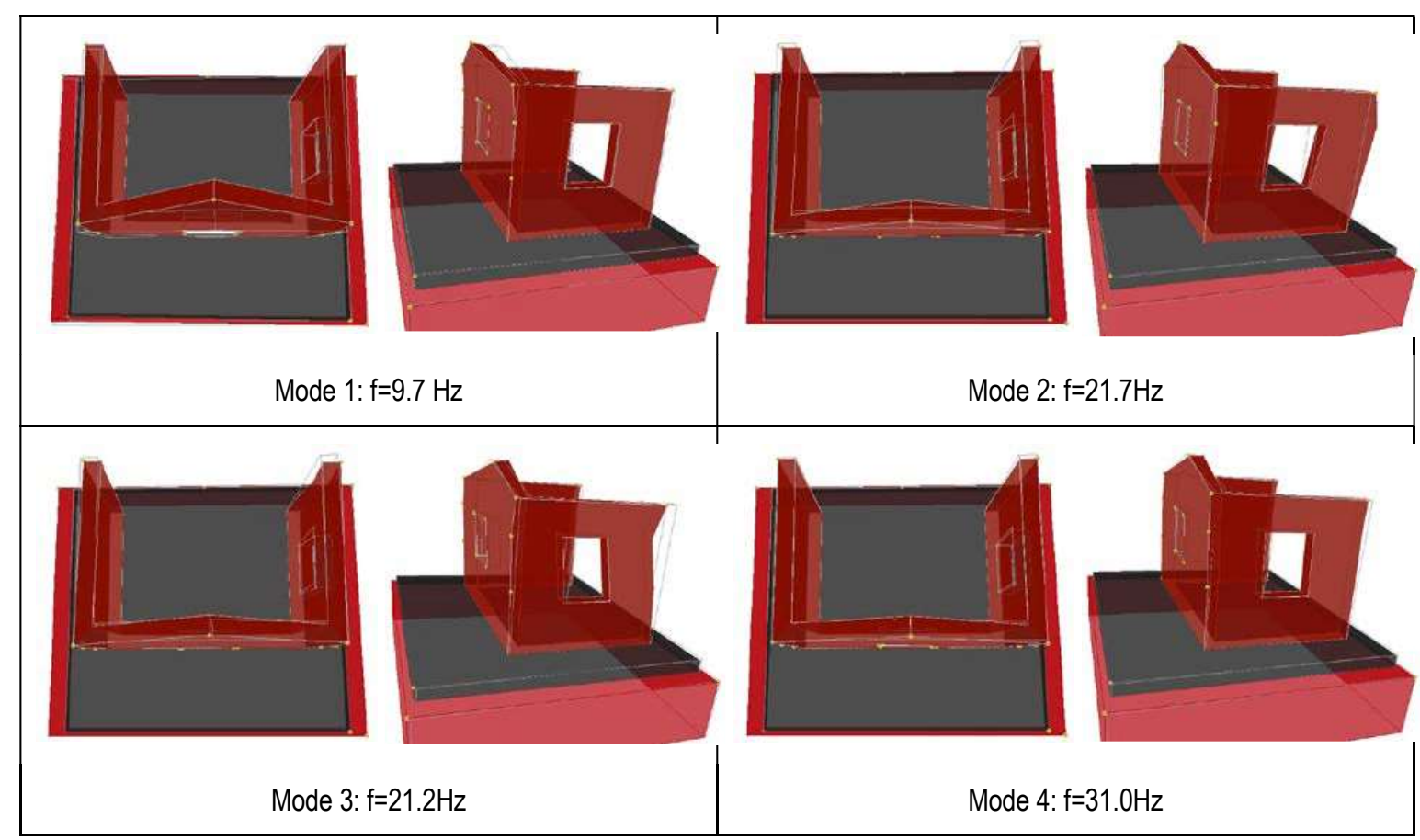

Figure 37 - Mode shapes for CAT09 of the Brick House mock-up 


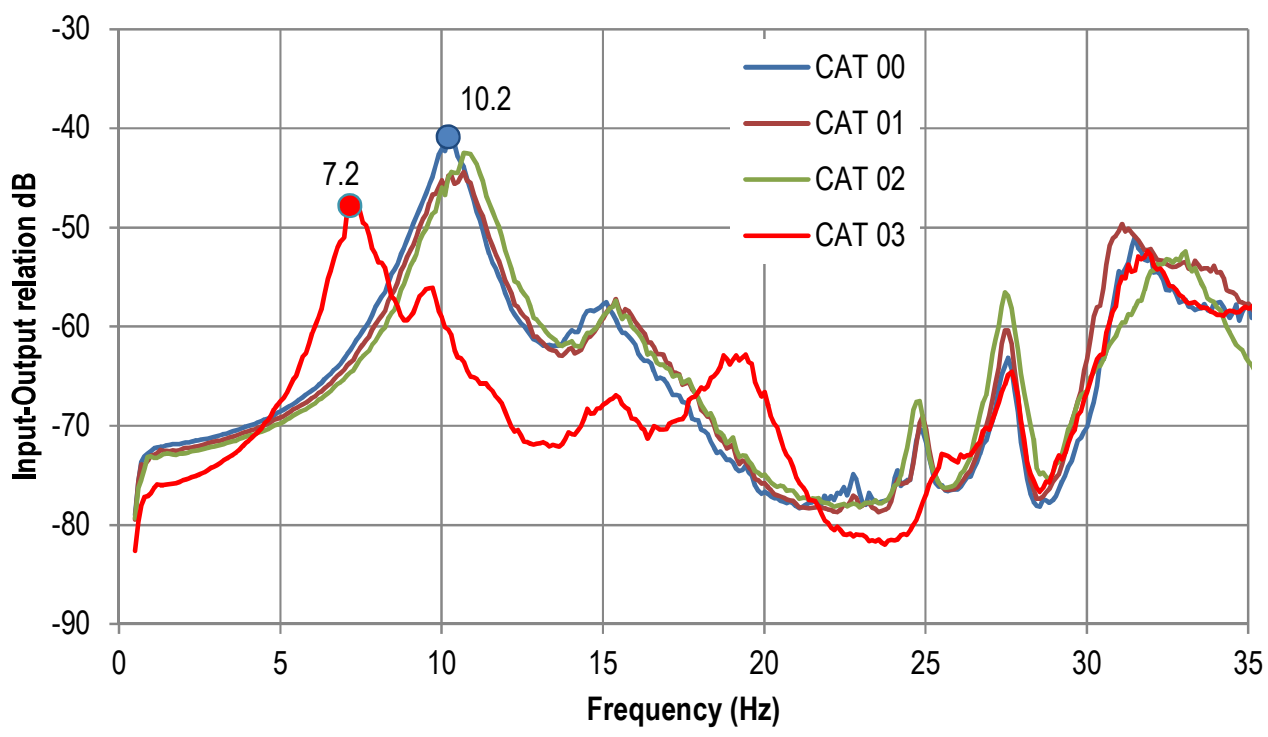

Figure 38 - Frequency domain decomposition for all dynamic identification of the Stone House mock-up 


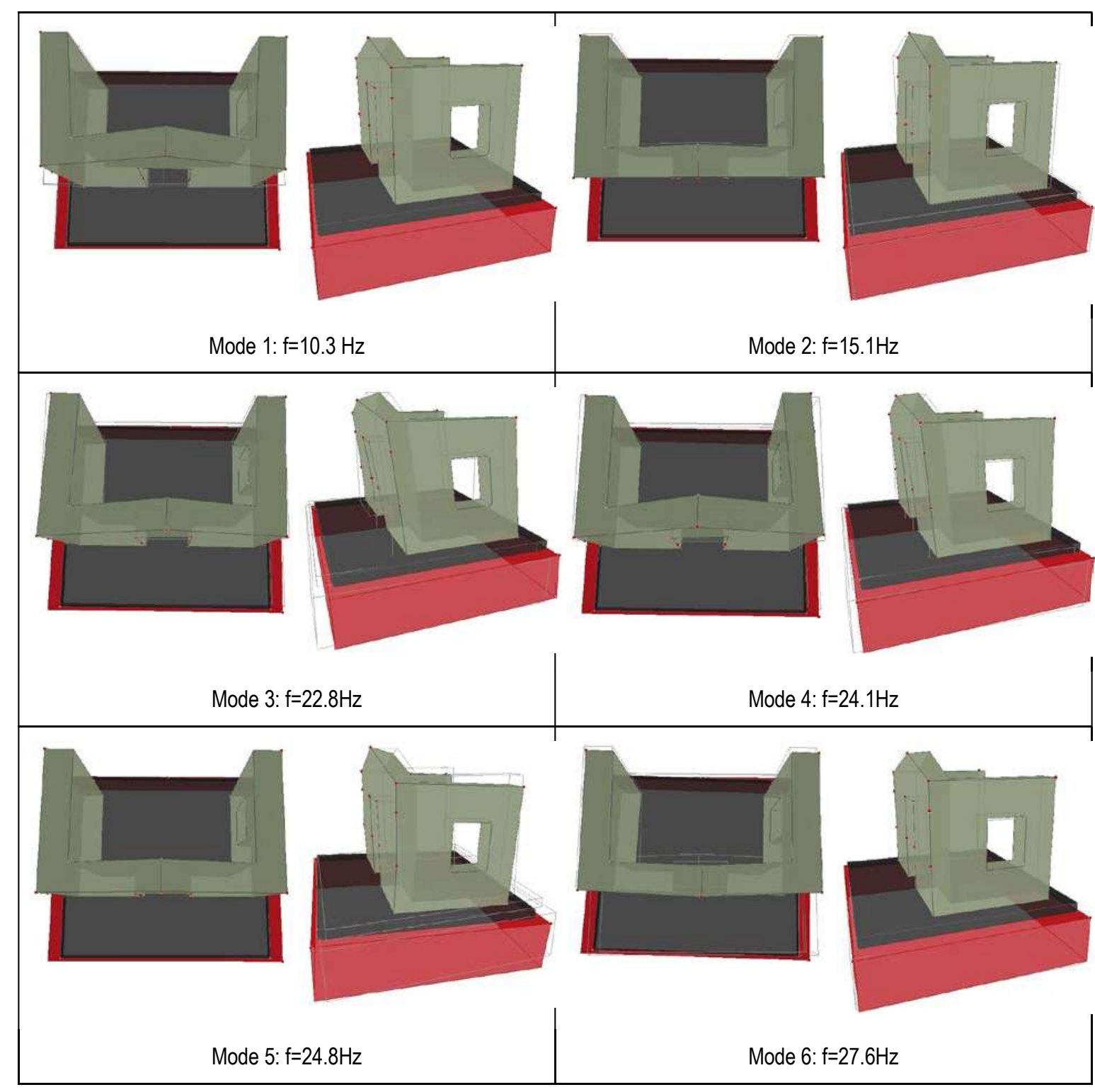

Figure 39 - Mode shapes for CATO0 of the Stone House mock-up 


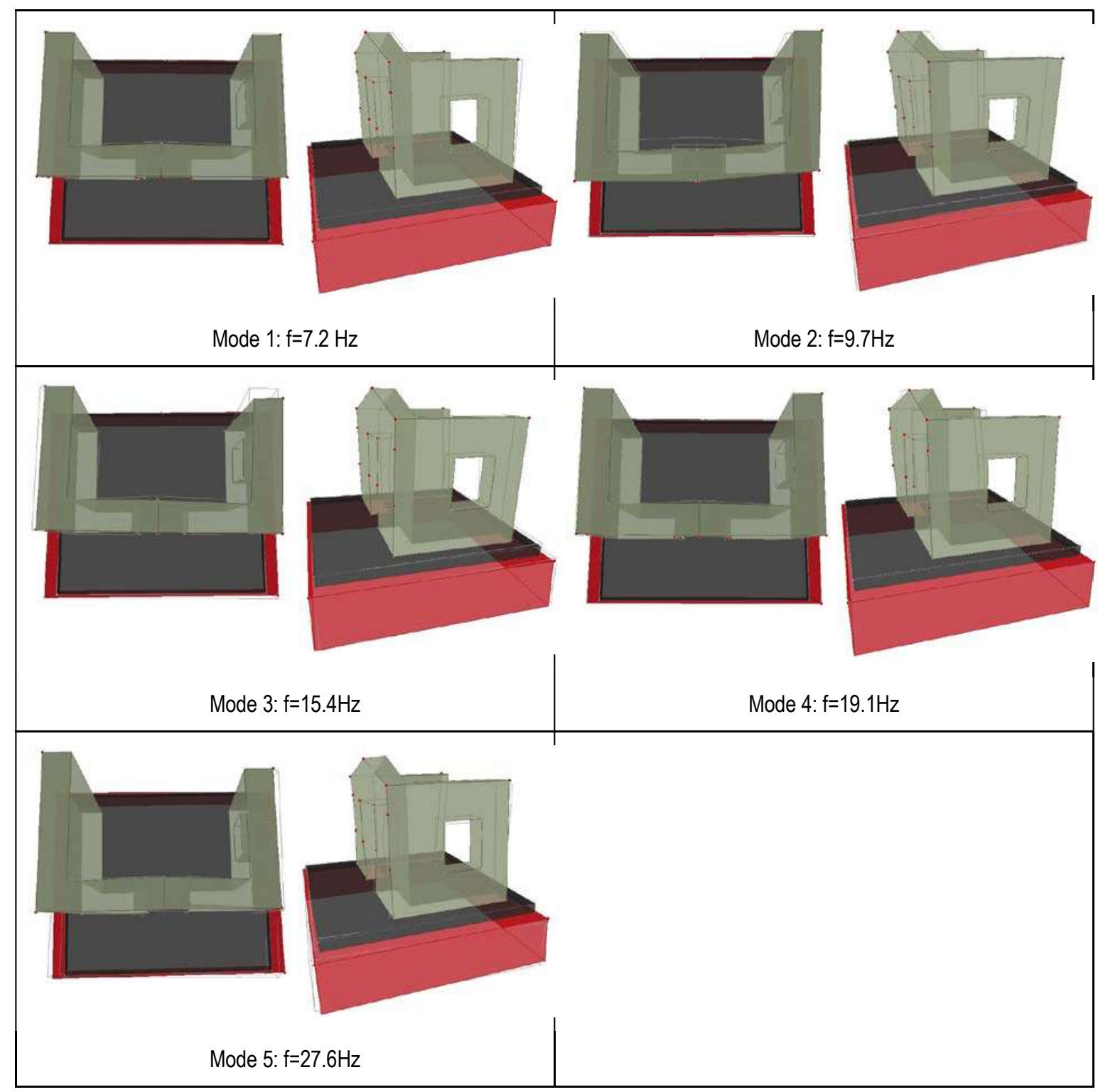

Figure 40 - Mode shapes for CAT03 of the Stone House mock-up 
Table 1 - Statistics from the mechanical characterization test results (brick masonry)

\begin{tabular}{|l|c|c|c|c|}
\hline & Specific mass & Young's modulus & $\begin{array}{c}\text { Compressive } \\
\text { strength }\end{array}$ & Tensile strength \\
\hline Number of samples & 6 & 3 & 3 & 3 \\
\hline Average & $1890 \mathrm{~kg} / \mathrm{m}^{3}$ & $5170 \mathrm{MPa}$ & $24.8 \mathrm{MPa}$ & $102 \mathrm{kPa}$ \\
\hline Coefficient of variation (COV) & $3 \%$ & $29 \%$ & $14 \%$ & $19 \%$ \\
\hline
\end{tabular}


Table 2 - Sample statistics from the mechanical characterization test results (stone masonry)

\begin{tabular}{|l|c|c|c|c|}
\hline & Specific mass & Young's modulus & $\begin{array}{c}\text { Compressive } \\
\text { strength }\end{array}$ & Tensile strength \\
\hline Number of samples & 6 & 3 & 3 & 3 \\
\hline Average & $2360 \mathrm{~kg} / \mathrm{m}^{3}$ & $2080 \mathrm{MPa}$ & $5.44 \mathrm{MPa}$ & $224 \mathrm{kPa}$ \\
\hline Coefficient of variation (COV) & $1 \%$ & $43 \%$ & $15 \%$ & $17 \%$ \\
\hline
\end{tabular}


Table 3 - List of accelerometers in the mock-ups

\begin{tabular}{|c|c|c|c|}
\hline Name & Location in the House & Direction & Units \\
\hline ACC01 & \multirow{2}{*}{ South wall, free corner } & Longitudinal (S to N) & \multirow{19}{*}[\mathrm{mg}]{} \\
\hline $\mathrm{ACC} 02$ & & Transverse (W to $\mathrm{E})$ & \\
\hline $\mathrm{ACC} 03$ & \multirow{3}{*}{ East façade, gable top } & Transverse $\mathrm{W}$ to $\mathrm{E}$ & \\
\hline $\mathrm{ACCO} 4$ & & Longitudinal $\mathrm{N}$ to $\mathrm{S}$ & \\
\hline ACC05 & & Vertical & \\
\hline ACC06 & \multirow{2}{*}{ North wall, free corner } & Longitudinal ( $\mathrm{N}$ to $\mathrm{S}$ ) & \\
\hline $\mathrm{ACC} 07$ & & Transverse (W to $\mathrm{E})$ & \\
\hline ACC08 & $\begin{array}{l}\text { East façade, windowsill level, } \\
\text { corner South side }\end{array}$ & \multirow{4}{*}{ Transverse (W to $\mathrm{E})$} & \\
\hline ACC09 & $\begin{array}{c}\text { East façade, windowsill level, } \\
\text { corner South side }\end{array}$ & & \\
\hline ACC10 & $\begin{array}{l}\text { East façade, windowsill level, } \\
\text { window North side }\end{array}$ & & \\
\hline ACC11 & $\begin{array}{c}\text { East façade, windowsill level, } \\
\text { corner North side }\end{array}$ & & \\
\hline ACC12 & $\begin{array}{c}\text { East façade, lintel level, corner } \\
\text { South side }\end{array}$ & \multirow{4}{*}{ Transverse (W to $\mathrm{E})$} & \\
\hline ACC13 & $\begin{array}{l}\text { East façade, lintel level, window } \\
\text { South corner }\end{array}$ & & \\
\hline ACC14 & $\begin{array}{c}\text { East façade, lintel level, window } \\
\text { North corner }\end{array}$ & & \\
\hline ACC15 & $\begin{array}{c}\text { East façade, lintel level, corner } \\
\text { North side }\end{array}$ & & \\
\hline ACC16 & \multirow{2}{*}{$\begin{array}{l}\text { East façade, top level, corner } \\
\text { South side }\end{array}$} & Transverse (W to $\mathrm{E})$ & \\
\hline ACC17 & & Longitudinal ( $\mathrm{N}$ to $\mathrm{S}$ ) & \\
\hline ACC18 & \multirow{2}{*}{$\begin{array}{l}\text { East façade, top level, corner } \\
\text { North side }\end{array}$} & Transverse (W to $\mathrm{E})$ & \\
\hline ACC19 & & Longitudinal (S to N) & \\
\hline
\end{tabular}


Table 4 - List of LVDTs in the mock-ups

\begin{tabular}{c|c|c|c}
\hline Name & $\begin{array}{c}\text { Location in the Brick } \\
\text { House }\end{array}$ & Direction & Units \\
\hline LVDT_1_Top_Central & Gable top & & \\
\cline { 1 - 2 } LVDT_2_Window_South & $\begin{array}{c}\text { Windowsill level, window } \\
\text { South corner }\end{array}$ & & \multirow{2}{*}{ Transverse (W to E) } \\
\cline { 1 - 2 } LVDT_3_Top_South & $\begin{array}{c}\text { Top level, wall South } \\
\text { corner }\end{array}$ & [mm] \\
\cline { 1 - 2 } LVDT_4_Base_Rel & Base & & \\
\hline LVDT_5_Window_North & $\begin{array}{r}\text { Windowsill level, window } \\
\text { North corner }\end{array}$ & & \\
\hline LVDT_6_Top_North & $\begin{array}{r}\text { Top level, wall North } \\
\text { corner }\end{array}$ & & \\
\hline
\end{tabular}


Table 5 - Brick House mock-up test sequence

\begin{tabular}{|c|c|c|c|c|}
\hline TEST & Target PGA [g] & PGA [g] & Signal & LTF File \\
\hline Dynamic characterization & - & - & WN & САT05 \\
\hline 01 & 0.282 & 0.179 & $100 \%$ Ref. & N64E_F_01 \\
\hline 02 & 0.282 & 0.292 & $100 \%$ Ref. & N64E_F_02 \\
\hline 03 & 0.282 & 0.358 & $100 \%$ Ref. & N64E_F_03 \\
\hline 04 & 0.564 & 0.405 & $200 \%$ Ref. & N64E_F_04 \\
\hline Dynamic characterization & - & - & WN & САТ06 \\
\hline 05 & 0.564 & 0.517 & $200 \%$ Ref. & N64E_F_05 \\
\hline Dynamic characterization & - & - & WN & САТ07 \\
\hline 06 & 0.564 & 0.782 & $200 \%$ Ref. & N64E_F_06 \\
\hline Dynamic characterization & - & - & WN & САТ08 \\
\hline 07 & 0.846 & 0.843 & $300 \%$ Ref. & N64E_F_07 \\
\hline Dynamic characterization & - & - & WN & САT09 \\
\hline 08 & 0.846 & 1.273 & $300 \%$ Ref. & N64E_F_08 \\
\hline
\end{tabular}


Table 6 - Stone House mock-up test sequence

\begin{tabular}{c|c|c|c|c}
\hline TEST & Target PGA [g] & PGA [g] & Signal & LTF File \\
\hline Dynamic characterization & - & - & WN & CAT00 \\
\hline 00 & 0.282 & 0.382 & $100 \%$ Ref. & N64E_F_00 \\
\hline 01 & 0.282 & 0.403 & $100 \%$ Ref. & N64E_F_01 \\
\hline 02 & 0.282 & 0.419 & $100 \%$ Ref. & N64E_F_02 \\
\hline Dynamic characterization & - & - & WN & CAT01 \\
\hline 03 & 0.564 & 0.657 & $200 \%$ Ref. & N64E_F_03 \\
\hline Dynamic characterization & - & - & WN & CAT02 \\
\hline 04 & 0.564 & 1.024 & $200 \%$ Ref. & N64E_F_04 \\
\hline 05 & - & - & WN & CAT03 \\
\hline Dynamic characterization & 0.564 & 1.051 & $200 \%$ Ref. & N64E_F_05 \\
\hline
\end{tabular}


Table 7 - Peak values of the reference and ST seismic signals for tests TEST03, TEST06 and TEST08 (Brick House)

\begin{tabular}{|c|l|c|c|c|}
\hline \multicolumn{2}{|c|}{ Seismic signals } & TEST03 & TEST06 & TEST08 \\
\hline \multirow{3}{*}{ Acceleration [g] } & Reference & 0.28 & 0.56 & 0.85 \\
\cline { 2 - 5 } & ST & 0.36 & 0.78 & 1.27 \\
\cline { 2 - 5 } & Difference & $29 \%$ & $39 \%$ & $49 \%$ \\
\hline \multirow{3}{*}{ Displacement [mm] } & Reference & 25.85 & 51.69 & 77.54 \\
\cline { 2 - 5 } & ST & 25.02 & 54.15 & 80.64 \\
\cline { 2 - 5 } & Difference & $-3 \%$ & $5 \%$ & $4 \%$ \\
\hline
\end{tabular}


Table 8 - MAC coefficients for the mode shapes in CAT06, CAT07, CAT08 and CAT09 (Brick House)

\begin{tabular}{|c|c|c|c|c|c|c|c|}
\hline Mode & & MOD_01_05 & MOD_02_05 & MOD_03_05 & MOD_04_05 & MOD_05_05 & MOD_06_05 \\
\hline & Freq. $(\mathrm{Hz})$ & 10.69 & 15.01 & 21.29 & 24.33 & 27.37 & 29.92 \\
\hline MOD_01_06 & 10.59 & $90 \%$ & $22 \%$ & $4 \%$ & $0 \%$ & $0 \%$ & $2 \%$ \\
\hline MOD_02_06 & 14.81 & $43 \%$ & $99 \%$ & $61 \%$ & $25 \%$ & $11 \%$ & $2 \%$ \\
\hline MOD_03_06 & 20.60 & $15 \%$ & $61 \%$ & $100 \%$ & $71 \%$ & $65 \%$ & $40 \%$ \\
\hline \begin{tabular}{|l|} 
MOD_04_06 \\
\end{tabular} & 23.93 & $37 \%$ & $7 \%$ & $2 \%$ & $6 \%$ & $1 \%$ & $0 \%$ \\
\hline MOD_05_06 & 27.17 & $0 \%$ & $4 \%$ & $45 \%$ & $38 \%$ & $97 \%$ & $70 \%$ \\
\hline MOD_06_06 & 30.02 & $3 \%$ & $0 \%$ & $19 \%$ & $34 \%$ & $40 \%$ & $92 \%$ \\
\hline MOD_01_07 & 10.59 & $98 \%$ & $36 \%$ & $11 \%$ & $1 \%$ & $0 \%$ & $1 \%$ \\
\hline MOD_02_07 & 14.52 & $40 \%$ & $51 \%$ & $13 \%$ & $4 \%$ & $0 \%$ & $0 \%$ \\
\hline MOD_03_07 & 20.01 & $13 \%$ & $56 \%$ & $99 \%$ & $71 \%$ & $70 \%$ & $45 \%$ \\
\hline MOD_04_07 & 23.35 & $12 \%$ & $10 \%$ & $6 \%$ & $18 \%$ & $4 \%$ & $0 \%$ \\
\hline MOD_05_07 & 27.07 & $1 \%$ & $0 \%$ & $28 \%$ & $29 \%$ & $87 \%$ & $67 \%$ \\
\hline MOD_06_07 & 30.02 & $6 \%$ & $1 \%$ & $10 \%$ & $27 \%$ & $29 \%$ & $84 \%$ \\
\hline MOD_01_08 & 10.59 & $93 \%$ & $39 \%$ & $14 \%$ & $1 \%$ & $1 \%$ & $1 \%$ \\
\hline MOD_02_08 & 14.52 & $35 \%$ & $93 \%$ & $85 \%$ & $44 \%$ & $32 \%$ & $12 \%$ \\
\hline MOD_03_08 & 16.97 & $6 \%$ & $33 \%$ & $86 \%$ & $74 \%$ & $83 \%$ & $58 \%$ \\
\hline MOD_04_08 & 21.97 & $3 \%$ & $2 \%$ & $9 \%$ & $10 \%$ & $69 \%$ & $54 \%$ \\
\hline MOD_05_08 & 26.58 & $10 \%$ & $14 \%$ & $1 \%$ & $6 \%$ & $43 \%$ & $43 \%$ \\
\hline MOD_06_08 & 31.09 & $23 \%$ & $25 \%$ & $3 \%$ & $1 \%$ & $5 \%$ & $27 \%$ \\
\hline MOD_01_09 & 9.71 & $0 \%$ & $26 \%$ & $74 \%$ & $58 \%$ & $70 \%$ & $46 \%$ \\
\hline MOD_02_09 & 21.68 & $12 \%$ & $32 \%$ & $4 \%$ & $0 \%$ & $19 \%$ & $21 \%$ \\
\hline MOD_03_09 & 27.17 & $18 \%$ & $38 \%$ & $9 \%$ & $0 \%$ & $7 \%$ & $9 \%$ \\
\hline MOD_04_09 & 31.00 & $26 \%$ & $36 \%$ & $5 \%$ & $2 \%$ & $6 \%$ & $32 \%$ \\
\hline
\end{tabular}


Table 9 - MAC coefficients for the mode shapes in CAT01, CAT02 and CAT03 (Stone House)

\begin{tabular}{|l|c|c|c|c|c|c|c|}
\hline Mode & & MOD_01_00 & MOD_02_00 & MOD_03_00 & MOD_04_00 & MOD_05_00 & MOD_06_00 \\
\hline & Freq. (Hz) & 10.3 & 15.1 & 22.8 & 24.1 & 24.8 & 27.6 \\
\hline MOD_01_01 & 10.2 & $100 \%$ & $9 \%$ & $7 \%$ & $17 \%$ & $33 \%$ & $32 \%$ \\
\hline MOD_02_01 & 15.4 & $4 \%$ & $98 \%$ & $4 \%$ & $40 \%$ & $5 \%$ & $13 \%$ \\
\hline MOD_03_01 & 22.8 & $8 \%$ & $20 \%$ & $95 \%$ & $59 \%$ & $0 \%$ & $2 \%$ \\
\hline MOD_04_01 & 24.1 & $18 \%$ & $39 \%$ & $67 \%$ & $89 \%$ & $3 \%$ & $20 \%$ \\
\hline MOD_05_01 & 24.9 & $29 \%$ & $4 \%$ & $1 \%$ & $2 \%$ & $98 \%$ & $62 \%$ \\
\hline MOD_06_01 & 27.6 & $28 \%$ & $18 \%$ & $0 \%$ & $38 \%$ & $55 \%$ & $97 \%$ \\
\hline & & & & & & & \\
\hline MOD_01_02 & 10.7 & $99 \%$ & $9 \%$ & $6 \%$ & $19 \%$ & $37 \%$ & $38 \%$ \\
\hline MOD_02_02 & 15.4 & $9 \%$ & $95 \%$ & $3 \%$ & $46 \%$ & $7 \%$ & $22 \%$ \\
\hline MOD_03_02 & 24.7 & $6 \%$ & $0 \%$ & $16 \%$ & $4 \%$ & $71 \%$ & $37 \%$ \\
\hline MOD_04_02 & 27.6 & $31 \%$ & $17 \%$ & $2 \%$ & $31 \%$ & $69 \%$ & $94 \%$ \\
\hline & & & & & & & \\
\hline MOD_01_03 & 7.2 & $85 \%$ & $5 \%$ & $6 \%$ & $18 \%$ & $40 \%$ & $38 \%$ \\
\hline MOD_02_03 & 9.7 & $33 \%$ & $46 \%$ & $7 \%$ & $27 \%$ & $40 \%$ & $44 \%$ \\
\hline MOD_03_03 & 15.4 & $12 \%$ & $7 \%$ & $2 \%$ & $32 \%$ & $4 \%$ & $7 \%$ \\
\hline MOD_04_03 & 19.1 & $0 \%$ & $2 \%$ & $1 \%$ & $10 \%$ & $2 \%$ & $14 \%$ \\
\hline MOD_05_03 & 27.6 & $4 \%$ & $13 \%$ & $1 \%$ & $2 \%$ & $11 \%$ & $10 \%$ \\
\hline
\end{tabular}

